\title{
Evaporation from Wavy Porous Surfaces into Turbulent Airflows
}

\author{
Erfan Haghighi $^{1}$ • Dani Or ${ }^{1}$
}

Received: 6 February 2015 / Accepted: 14 May 2015 / Published online: 26 May 2015

C Springer Science+Business Media Dordrecht 2015

\begin{abstract}
The relief and roughness of natural surfaces interacting with airflows and with radiation affect rates and distributions of heat and vapor fluxes into the atmosphere. The study quantifies interactions of regular sinusoidal wavy porous surfaces (with different geometrical characteristics) affecting heat and vapor transport into prescribed turbulent airflows. A model for turbulent eddies interacting with an undulating evaporating surface with mean boundary layer that varies across sinusoidal wavy surfaces was developed and experimentally evaluated in a wind tunnel. The surface of a $1 \mathrm{~m}^{2}$ shallow ( $0.3 \mathrm{~m}$ deep) sand-filled basin was imprinted with regular sinusoidal ridges and troughs; water content and temperature sensors were embedded in the sand, and the instrumented basin was placed on a balance in the wind tunnel. Detailed thermal signatures of the evaporating surface for different wind speeds and surface patterns were obtained using high-resolution infrared thermography. The evaporative mass loss measurements and observed thermal patterns were in good agreement with model predictions for turbulent exchange over various wavy sand surface geometries. Results suggest that evaporative fluxes can be either enhanced or suppressed (relative to a flat surface) due to complex interplay between local boundary layer thickness and internal limitations to water flow to the evaporating surface. For a practical range of air velocities $(0.5-4.0 \mathrm{~m} / \mathrm{s})$, and for sinusoidal configurations studied (amplitudes of 50-100 mm), the evaporative mass loss (relative to the flat surface) was reduced by up to $60 \%$ for low surface aspect ratio and high wind velocity, and enhanced by up to $80 \%$ for high aspect ratio and low wind velocity. The study offers a framework for interpreting and upscaling evaporative fluxes from rough terrestrial surfaces. Ongoing work considers shortwave radiation and geometrical interactions for a more complete account of surface energy balance and fluxes from natural rough surfaces.
\end{abstract}

Keywords Evaporation · Porous media - Wavy surface · Turbulent airflow · Surface decoupling

Erfan Haghighi

erfan.haghighi@usys.ethz.ch

1 Soil and Terrestrial Environmental Physics, Department of Environmental Systems Science, ETH Zurich, Universitätstrasse 16, 8092 Zürich, Switzerland 


\section{List of symbols}

$A_{\mathrm{b}} \quad$ Surface area of wavy building block $\left(\mathrm{m}^{2}\right)$

$C_{\mathrm{a}} \quad$ Vapor concentration in air $\left(\mathrm{kg} / \mathrm{m}^{3}\right)$

$C_{\mathrm{s}} \quad$ Saturated vapor concentration $\left(\mathrm{kg} / \mathrm{m}^{3}\right)$

$c_{1} \quad$ Coefficient in Eq. (1) (-)

$c_{2} \quad$ Coefficient in Eq. (4) (-)

$c_{3} \quad$ Coefficient in Eq. (4) (-)

$c_{4} \quad$ Coefficient in Eq. (8) (-)

$c_{p} \quad$ Air-specific heat capacity $(\mathrm{J} / \mathrm{kg} \mathrm{K})$

$D$ Water vapor diffusion coefficient in air $\left(\mathrm{m}^{2} / \mathrm{s}\right)$

E Evaporation flux $\left(\mathrm{kg} / \mathrm{m}^{2} \mathrm{~s}\right)$

$E^{\mathrm{o}} \quad$ Potential evaporation flux $\left(\mathrm{kg} / \mathrm{m}^{2} \mathrm{~s}\right)$

$e \quad$ Total evaporation rate $(\mathrm{kg} / \mathrm{s})$

$e_{\mathrm{b}} \quad$ Evaporation rate from wavy building block $(\mathrm{kg} / \mathrm{s})$

$g_{\mathrm{h}} \quad$ Aerodynamic conductance $(\mathrm{m} / \mathrm{s})$

$H \quad$ Drying front depth (m)

$H_{\mathrm{C}} \quad$ Evaporative characteristic length (m)

$H_{\mathrm{G}} \quad$ Gravity characteristic length (m)

$H_{\mathrm{wt}}$ Water table depth measured from ridges (m)

$K_{\mathrm{a}} \quad$ Air thermal conductivity (W/mK)

$K_{\text {eff }}$ Effective hydraulic conductivity $(\mathrm{m} / \mathrm{s})$

$K_{\text {s }} \quad$ Saturated hydraulic conductivity $(\mathrm{m} / \mathrm{s})$

$\ell \quad$ Length of evaporating system (m)

$M_{\mathrm{w}} \quad$ Molar mass of water $(\mathrm{kg} / \mathrm{mol})$

$m \quad$ Largest integer smaller than $\alpha(-)$

$N_{\mathrm{b}} \quad$ Number of wavy building blocks (-)

$n \quad$ Pore size distribution index (-)

$P_{\text {sat }} \quad$ Saturated vapor pressure $(\mathrm{Pa})$

$R_{\mathrm{BL}}$ Boundary layer resistance ( $\left.\mathrm{s} / \mathrm{m}\right)$

$R_{\mathrm{Sv}} \quad$ Capillary-viscous resistance (s/m)

$\mathrm{Re}_{\mathrm{K}}$ Permeability Reynold number (-)

RH Relative humidity (-)

$\Re \quad$ Universal gas constant $(\mathrm{J} / \mathrm{mol} \mathrm{K})$

$r \quad$ Mean pore radius $(\mathrm{m})$

$s \quad$ Length of wavy building block (m)

$T_{\mathrm{a}} \quad$ Air temperature (K)

$T_{\mathrm{S}} \quad$ Surface temperature $(\mathrm{K})$

$t \quad$ Eddy residence time (s)

$U_{\text {a }}$ Air velocity $(\mathrm{m} / \mathrm{s})$

$w \quad$ Width of wavy building block and evaporating system (m)

$x \quad$ Distance along $x$-axis (m)

$x_{\mathrm{r}} \quad$ Reattachment point $(\mathrm{m})$

$x_{\mathrm{S}} \quad$ Separation point $(\mathrm{m})$

$Z_{\mathrm{T}} \quad$ Height of trough above water table (m)

$\alpha \quad$ Shape parameter of eddy residence time distribution (-)

$\alpha_{\mathrm{s}} \quad \alpha$ over separation zone (-)

$\chi \quad$ Surface wetness-dependent coefficient of $K_{\text {eff }}(-)$ 
$\delta \quad$ Viscous sublayer thickness (m)

$\gamma \quad$ Amplitude of wavy building block (m)

$\lambda \quad$ Wavelength of wavy building block $(\mathrm{m})$

$v \quad$ Air kinematic viscosity $\left(\mathrm{m}^{2} / \mathrm{s}\right)$

$\Theta_{\text {surf }}$ Effective surface water saturation (-)

$\theta_{\mathrm{r}} \quad$ Residual water content (-)

$\theta_{\mathrm{s}} \quad$ Saturated water content (-)

$\theta_{\text {surf }}$ Surface water content (-)

$\rho \quad$ Water density $\left(\mathrm{kg} / \mathrm{m}^{3}\right)$

$\rho_{\mathrm{a}} \quad$ Air density $\left(\mathrm{kg} / \mathrm{m}^{3}\right)$

$\tau \quad$ Tortuosity (-)

\section{Introduction}

The relief and roughness of natural soil surfaces is manifested across many scales and affect many land-atmosphere interactions (Jalota and Prihar 1990; Raupach et al. 1992; McInnes et al. 1994; Raupach and Finnigan 1997). We distinguish between surface roughness that refers to microrelief of soil surfaces due to variations and arrangement of soil aggregates (Lehrsch et al. 1987; Guzha 2004) from the general relief of a surface that represents topographical structures that are many times larger than soil aggregates. Studies of heat and mass transfer from terrestrial surfaces have shown that land relief and surface roughness may affect the surface reflectively (albedo) hence the amount of shortwave radiation absorbed at the surface (Bowers and Hanks 1965; Potter et al. 1987; Raupach and Finnigan 1997; Matthias et al. 2000; Cierniewski et al. 2014). Surface roughness and relief have also been shown to act as momentum sinks for the atmospheric flows (Raupach 1992) affecting the aerodynamic boundary layer and turbulent interactions adjacent to the surface (Perry et al. 1969; Taylor and Gent 1974; Finnigan 1988; Wieringa 1993; Raupach and Finnigan 1997). Such effects of surface geometrical irregularities on incoming shortwave radiation and on aerodynamic boundary layer near the surface, in turn, affect exchange of energy, water, and momentum between land surfaces and the atmosphere (Jalota and Prihar 1990; Raupach et al. 1992; McInnes et al. 1994; Raupach and Finnigan 1997).

A simple example of terrestrial surfaces with regular variations in surface relief are agricultural ridge-furrow surfaces that have been known to affect aerodynamic properties, and heat and vapor exchange dynamics at the surface (Potter et al. 1987; Jalota and Prihar 1990; McInnes et al. 1994). Studies have shown that short-term evaporation rates increase over such (wavy) soil surfaces (relative to a similar untilled surface) (Holmes et al. 1960; Allmaras et al. 1972; Jalota and Prihar 1990), whereas longer-term evaporation rates exhibited a decrease (Willis and Bond 1971; Gill et al. 1977; Jalota and Prihar 1990). Under certain conditions surface tillage has been used to conserve water, but it may also enhance evaporation and thus accelerate soil drying (Jalota and Prihar 1990; Unger and Cassel 1991; Schwartz et al. 2010). These seemingly inconsistent effects point to the complexity and modifications of surface geometrical features on interactions that are otherwise reasonably well understood for flat and smooth surfaces.

Notwithstanding the large number of experimental studies on interactions influencing heat and mass exchange from tilled soil surfaces (e.g., Jalota and Prihar 1990; Unger and Cassel 1991; McInnes et al. 1994), there are only a handful of mechanistic models that systematically account for interactions among key processes (Linden 1982; Bristow et al. 1986; Yang et al. 1996; Mwendera and Feyen 1997). The primary objective of this study was to develop a 


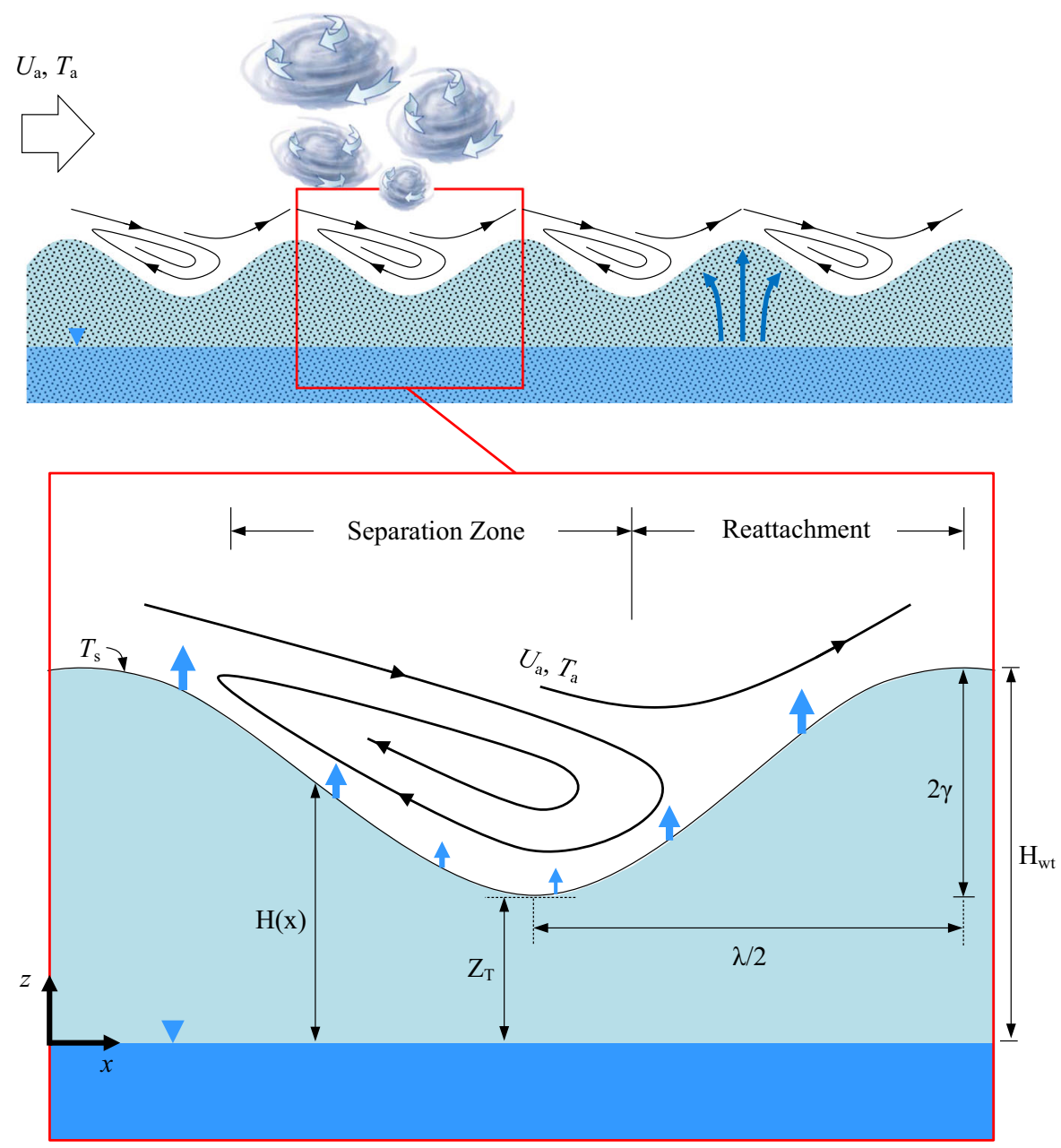

Fig. 1 Schematic of pore-scale evaporation from a sinusoidal wavy porous surface (characterized by wave amplitude $2 \gamma$ and wavelength $\lambda$ ), in the presence of a shallow water table, into a turbulent airflow boundary layer. At aspect ratios $(2 \gamma / \lambda)$ larger than 0.03 , airflow boundary layer detaches wavy surfaces of heights larger than the viscous sublayer thickness $(\delta / 2 \gamma<1)$, and a separated flow region forms in the wake of ridges when the bulk flow is perpendicular to the direction of ridges. Local evaporative fluxes from the surface are affected by spatial variations of (1) internal soil hydraulic properties reflected in surface water content and ridges surface decoupling from the water table below and (2) external airflow boundary layer dynamics that locally vary along the wavy surface

simple and physically based model for quantifying evaporation from sinusoidal wavy porous surfaces during stage-I evaporation. The model considers sinusoidal surfaces characterized by wave amplitude $(2 \gamma)$ and wavelength $(\lambda)$, and the effects of various physical processes that influence evaporative fluxes and surface temperatures (see Fig. 1).

Soil evaporation during stage-I may be limited by internal transport properties that affect water supply to the vaporization plane at the surface (van Brakel 1980; Prat 2002; Lehmann et al. 2008; Shokri et al. 2010; Haghighi et al. 2013); or by available energy at the surface (Penman 1948); and by mass exchange resistance across a thin boundary layer adjacent to 
the surface (termed the viscous sublayer) where exchange rates are dominated by molecular diffusion (Oke 1978; Schlünder 1988; Shahraeeni et al. 2012; Haghighi et al. 2013). In recently established pore-scale models for evaporation from flat (and smooth) porous surfaces exposed to a convective air boundary layer, diffusive fluxes across the viscous sublayer were calculated by explicit incorporation of the dynamic resistance due to changes in surface water content and capillary connections to the subsurface (Shahraeeni et al. 2012; Haghighi et al. 2013). Additionally, airflow turbulence and its impacts on the viscous sublayer thickness were incorporated via the surface renewal (SR) formalism (Higbie 1935; Danckwerts 1951; Harriott 1962) considering surface-eddy exchange during an eddy's residence time over a surface (Haghighi and Or 2013).

We seek to integrate effects of wavy surface attributes on surface wetness and on the aerodynamic boundary layer forming adjacent to an evaporating surface. Hence, the specific objectives of this study were to (1) extend the evaporation model of Haghighi et al. (2013) for turbulent interactions with wavy porous surfaces considering renewal eddy characteristics and mean viscous sublayer variations across the wavy surface (see Fig. 2); (2) experimentally test the model by systematically varying wavy surface attributes in evaporation experiments in a wind tunnel; and (3) express the effective behavior of surface waviness on evaporative fluxes relative to flat surfaces under similar boundary conditions.

Following this introduction, we present in Sect. 2 theoretical background and modeling details for coupling pore-scale evaporation from wavy porous surfaces with a collection of individual eddies forming the interacting turbulent airflow. Section 3 is devoted to describing experimental setup used for evaluating the proposed model by first considering surface thermal patterns observable by infrared thermography (IRT), and then mass loss measurements. Preliminary experimental results and model verifications are presented in Sect. 4, followed by summary and concluding remarks in Sect. 5 .

\section{Modeling Evaporation from Wavy Porous Surfaces}

Studies have shown that local and mean evaporative fluxes from wet porous surfaces are constrained by hydration condition and transport properties of the porous medium, and by vapor transport across the air viscous sublayer adjacent to the surface (Schlünder 1988; Lehmann et al. 2008; Shahraeeni et al. 2012; Haghighi et al. 2013). Thus, understanding effects of surface relief on subsurface hydrologic processes and on interacting airflows is essential for parameterization of momentum, heat, and mass transfer processes from wet surfaces to the airflow. Waviness is the measure of surface relief at scales and spacing much greater than surface grain and other roughness elements that does not behave like a surface roughness in a traditional sense (Schultz and Flack 2009). We characterize regular surface waviness by an aspect ratio $2 \gamma / \lambda(-)$ with wave amplitude $2 \gamma(\mathrm{m})$ and wavelength $\lambda(\mathrm{m})$ (see Fig. 1).

For a prescribed wavy surface of wavelength $\lambda$, the variations in wave amplitude $2 \gamma$ or its aspect ratio $(2 \gamma / \lambda)$ can significantly affect the behavior of a turbulent airflow boundary layer perpendicular to the direction of ridges (Bradshaw 1973; Zilker and Hanratty 1979; Buckles et al. 1984; Baskaran et al. 1987). The magnitude of this effect depends on the ratio of the upwind shear layer thickness ( $\delta_{x=0}$, defined in Sect. 2.1 below) to the wave amplitude $(2 \gamma)$ (Baskaran et al. 1987) such that for a ratio $\delta / 2 \gamma<1$ flow separates due to a strong adverse pressure gradient established in the lee of the ridges (Baskaran et al. 1987; Almeida et al. 1993; Raupach and Finnigan 1997). According to Simpson (1989), the flow separation is defined as the complete process of departure, detachment, or breakdown of the boundary 
layer flow. The detachment is accompanied by a sudden thickening of the rotational flow near the wall and by large values of the normal component of the velocity at the wall. For conditions with $\delta / 2 \gamma>1$ (very low wind speeds or low-amplitude surface relief), the airflow traces the surface, and boundary layer separation does not occur (Baskaran et al. 1987; Almeida et al. 1993).

For sufficiently high wind velocity, a new condition (in addition to $\delta / 2 \gamma<1$ ) stipulates that a surface aspect ratio $2 \gamma / \lambda$ larger than 0.03 is required for flow separation (Zilker and Hanratty 1977, 1979). Studies of steady turbulent flows (where mean turbulence characteristics remain constant with time) have shown that for wavy surfaces with aspect ratios larger than 0.03 , the boundary layer detaches and results in separated flow regions in the wake of ridges (Zilker and Hanratty 1977, 1979). For a wide range of Reynolds numbers and surface wave geometry, experimental and numerical studies have shown that flow transverse to a smooth wavy surface separates near $x_{\mathrm{s}}=0.1 \lambda$ and reattaches near $x_{\mathrm{r}}=0.6 \lambda$ (Buckles et al. 1984; Almeida et al. 1993; Maaß and Schumann 1996; Kruse et al. 2006; Wagner et al. 2011). A similar pattern of wavy surface influence on airflow interactions (expressed in terms of boundary layer resistance) was deduced from observations over wavy bare soil surfaces subjected to natural air boundary layer (McInnes et al. 1994). Considering that for many natural surfaces the ratio $2 \gamma / \lambda$ is often greater than 0.1 , it is reasonable to expect the zones of separated and reattached airflows to form between ridges for airflows perpendicular to the ridge orientation (Fig. 1).

In addition to effects on airflow conditions and the patterns of aerodynamic boundary layer near the surface, surface attributes may influence local hydrological interactions affecting surface water content distribution along a wavy porous surface. During stage-I evaporation, water is supplied to the evaporation plane at the surface via continuous liquid pathways driven by capillary gradients acting against gravitational pull and viscous resistance (Yiotis et al. 2001; Lehmann et al. 2008; Shokri et al. 2010). Modifying aerodynamic boundary layer and thus evaporative fluxes, surface waviness affects the initial hydrostatic conditions influencing dynamic conditions. These local effects may alter the competition between capillary, gravity, and viscous effects that, in turn, affects local distribution of surface water content and resulting evaporative fluxes.

In the following, we first describe how the local viscous sublayer thickness, as a key variable that determines the upper boundary condition for diffusive heat and mass exchange (Gaikovich 2000; Shahraeeni et al. 2012; Haghighi and Or 2013), is affected along a prescribed wavy geometry (Section 2.1). This localized parameterization of the boundary layer is then applied to the pore-scale diffusion model to quantify local (and mean) evaporation rates (Sects. 2.2 and 2.3). We extend the diffusion-based resistance model of Haghighi et al. (2013) coupled with concepts from the SR theory (Brutsaert 1975; Haghighi and Or 2013) by incorporating the role of wavy surface variables on the localization of the viscous sublayer thickness and on capillary water flow to the evaporating surface at the pore-scale, as depicted in Fig. 2. Notwithstanding potential effects of surface roughness on the dynamics of boundary layer separation along a bare tilled soil surface, the boundary layer separation and reattachment points are assumed to follow a similar pattern as for smooth surfaces (McInnes et al. 1994). We also neglect potential effects of wind penetration into evaporating porous surfaces, simply because water-filled pores during stage-I evaporation would suppress such convection into the porous medium (Kimball and Lemon 1971; Massman et al. 1997), and the permeability Reynolds number $\mathrm{Re}_{\mathrm{K}}$ (the ratio of effective pore diameter to typical thickness of the viscous sublayer) (Breugem et al. 2006) is negligibly small. Typical turbulent airflows with millimetric viscous sublayer (Haghighi and Or 2013) over soil surfaces of micrometric pore sizes would result in a negligibly small $\mathrm{Re}_{\mathrm{K}}$, with practically impervious surfaces 


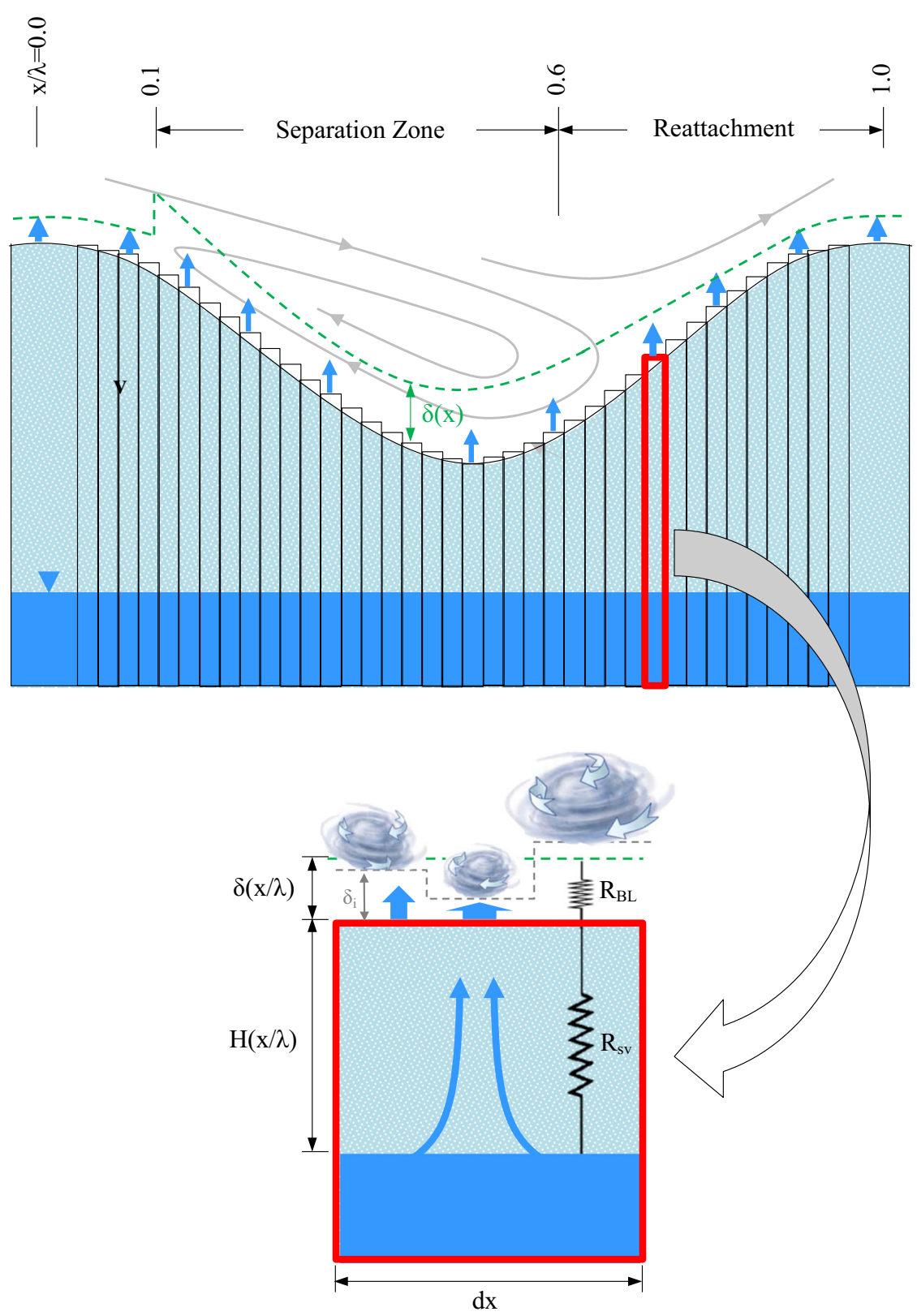

Fig. 2 Representation of an evaporating wavy surface building block as a collection of individual flat-surface evaporating sites with associated internal and external boundary conditions (note that dimensions are not to scale). Evaporative fluxes from each flat-surface unit cell could be estimated from surface resistance model of Haghighi et al. (2013) coupled with concepts from the SR theory (Haghighi and Or 2013). The model considers surface-eddy interactions during their finite residence time over the surface. As eddies are being swept along the surface, they become gradually loaded by diffusing vapor (or exchange heat) across a viscous sublayer that forms at their footprint area (the interacting area with the surface). Eddies are eventually ejected back to the turbulent flow and subsequently replaced by new eddies. These local evaporative fluxes are averaged over the entire surface yielding mean evaporation flux from the wavy surface building block 


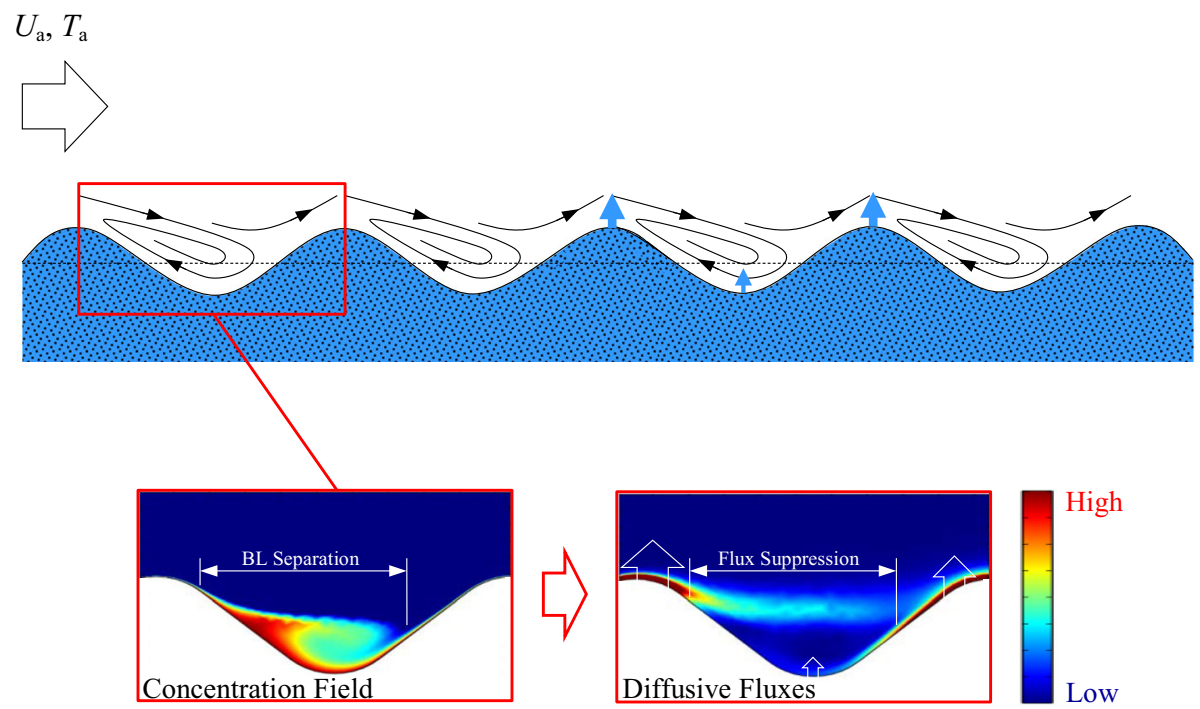

Fig. 3 Contribution of airflow boundary layer dynamics over a fully saturated wavy porous surface (with $H(x)=0$ below the surface) to local evaporative fluxes from the surface. Evaporative fluxes are controlled solely by aerodynamic properties parameterized by the viscous sublayer thickness $(\delta)$ such that airflow separation modifies local heat and mass exchange rates relative to a corresponding flat surface (indicated by the dashed line). The insets show a typical water vapor concentration field and a corresponding diffusive flux distribution adjacent to the wavy surface obtained from RANS simulation of turbulent water vapor transfer using COMSOL Multiphysics

(Breugem et al. 2006). We defer the treatment of shortwave radiation and associated geometrical interactions on localized surface energy balance to future studies, and focus here on laboratory-scale experiments in the absence of shortwave radiation.

\subsection{Local Variations of the Viscous Sublayer Thickness Along a Wavy Surface}

As discussed in the previous section, turbulent airflow over a wavy surface (at the scale of hydrological interest here) is characterized by flow separation and reattachment, and the formation of a recirculation zone (Figs. 1, 2) (Zilker and Hanratty 1979; Buckles et al. 1984; Cherukat et al. 1998; Wagner et al. 2011). The resulting separation zone modifies the local nature of the wind stress and accordingly local heat and mass exchange rates from the wavy surface (Fig. 3) (McInnes et al. 1994; Reul et al. 2008; Wagner et al. 2011; Mirzaei et al. 2013). A typical numerical simulation of evaporation from a fully saturated wavy surface (no internal flow limitations) as depicted in Fig. 3 reveals effects of variations in viscous sublayer thickness across the wavy surface on local variations in evaporative fluxes. The reduced vapor concentration gradient $(\mathrm{d} C / \mathrm{d} z)$ observed over the separation zone suppresses local evaporative fluxes that could be accounted for by a thicker viscous sublayer thickness (relative to the reattachment zone) resulting from the boundary layer separation.

Invoking concepts from the SR formalism, turbulent airflow interactions are considered by averaging the effects of eddies over their sizes and intensities in the population (Harriott 1962; Brutsaert 1975; Haghighi and Or 2013). A characteristic viscous sublayer forms under each eddy that provides boundary conditions for vapor and heat transfer (see Fig. 2) (Gaikovich 2000; Haghighi and Or 2013, 2015a). Motivated by Meek and Baer's (1970, 1973) study, 
Haghighi and Or (2013) have estimated the thickness of the viscous sublayer forming below an eddy's footprint, $\delta_{i}(\mathrm{~m})$, over a flat surface as a function of eddy residence time, $\tau_{i}(\mathrm{~s})$, as (Fig. 2)

$$
\delta_{i}=c_{1} \sqrt{v t_{i}}
$$

where $c_{1}=2.2$ is a proportionality constant depending on flow geometry (Popovich and Hummel 1967; Meek and Baer 1973; Tuoc and Keey 1992; Haghighi and Or 2013), $v\left(\mathrm{~m}^{2} / \mathrm{s}\right)$ is the kinematic viscosity of air $\left(1.5 \times 10^{-6} \mathrm{~m}^{2} / \mathrm{s}\right)$, and $t_{i}(\mathrm{~s})$ is the residence time of the $i$ th eddy. Considering an eddy residence time distribution (parametrically expressed by the gamma statistical distribution (Danckwerts 1951; Seo and Lee 1988)), an effective viscous sublayer thickness as a function of turbulent flow characteristics that explicitly considers the influence of the eddy distribution on mass exchange processes is established according to (see Fig. 2) (Haghighi and Or 2013)

$$
\delta=\frac{v}{0.3 U_{a}} g(\alpha) \cdot(\alpha+1)
$$

where $U_{\mathrm{a}}(\mathrm{m} / \mathrm{s})$ is the mean ambient velocity, $\alpha(-)$ is the shape parameter of eddy residence time distribution ranging from 0 to 2 for a range of practical airflow conditions interacting with flat (and smooth) surfaces (Haghighi and Or 2013, 2015a), and $g(\alpha)$ is obtained from (Haghighi and Or 2013)

$$
\begin{aligned}
& g(\alpha)=\frac{2.2 \sqrt{112 \pi}}{\Gamma(\alpha+1)} \frac{1}{2^{(\alpha+1)} \sqrt{\alpha+1}} \cdot \begin{cases}1 & \alpha=0 \\
\Pi(2 \alpha+1) & \alpha>0\end{cases} \\
& \Pi(2 \alpha+1)=(2 \alpha+1) \cdot(2(\alpha-1)+1) \cdot(2(\alpha-2)+1) \cdot \ldots \cdot(2(\alpha-m)+1), \quad m<\alpha
\end{aligned}
$$

with $m(-)$ the largest integer smaller than $\alpha$.

The parametric viscous sublayer model above, established for flat surfaces, was extended to consider local interactions of the viscous sublayer thickness along a wavy surface for mean airflow perpendicular to the ridges. The model extension considers a separated flow region underlain by spanwise oriented large eddies with the reattachment zone experiencing a turbulent regime dominated by small-scale streamwise eddies (Wagner et al. 2011), as depicted in Figs. 1 and 2. Employing Eq. (2) that defines the mean viscous sublayer thickness above a single flat-surface unit cell forming the wavy surface (see Fig. 2), the expressions for the resulting mean boundary layer thickness at the various regions of a wavy surface element are given as follows

$$
\begin{aligned}
\delta(x / \lambda) & = \begin{cases}\frac{v}{0.3 U_{a}} g(\alpha) \cdot(\alpha+1) & 0.0 \leq x / \lambda<0.1 \\
\frac{v}{0.3 U_{a}} g\left(\alpha_{s}\right) \cdot\left(\alpha_{s}+1\right) & 0.1 \leq x / \lambda \leq 0.6 \\
c_{2} \frac{x}{\lambda}+c_{3} & 0.6<x / \lambda \leq 1.0\end{cases} \\
c_{2} & =\frac{v}{0.3 U_{a}} \frac{g(\alpha) \cdot(\alpha+1)-g\left(\alpha_{s}\right) \cdot\left(\alpha_{s}+1\right)}{1-0.6} \\
c_{3} & =\frac{v}{0.3 U_{a}} g(\alpha) \cdot(\alpha+1)-c_{2}
\end{aligned}
$$

The expressions in Eq. (4) are in the core of this study where we capitalize on the average and scalable behavior of separation and reattachment zones over wavy surfaces to derive analytical expressions for the spatially resolved boundary layer thickness. The simplification implicit in the linear variation of the mean viscous sublayer thickness over the reattachment zone $(0.6<x / \lambda \leq 1.0)$ was inspired by the results of McInnes et al. (1994) that observed a 

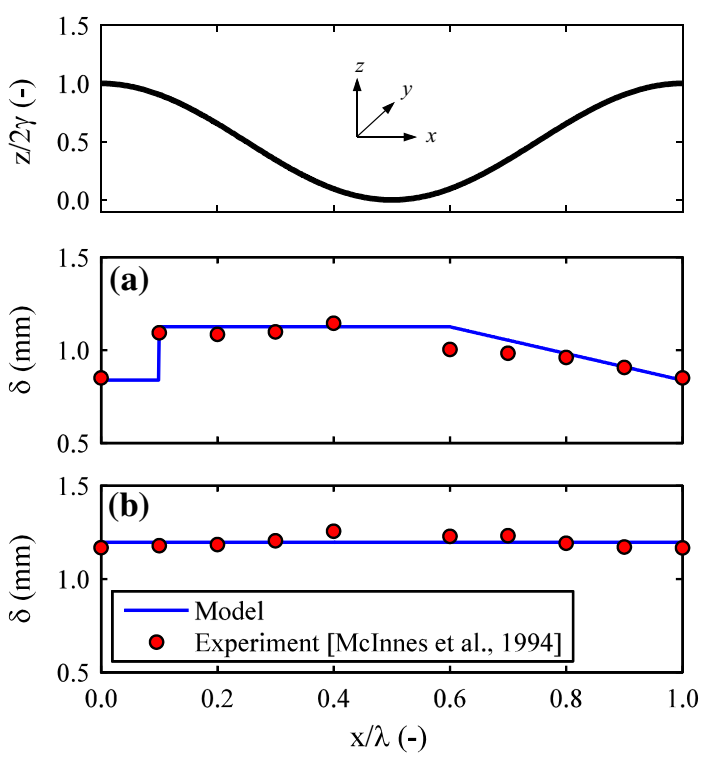

Fig. 4 Comparison of predicted (lines) and measured (symbols) variations in the viscous sublayer thickness along a wavy surface (in $x$-direction) when wind direction is in $\mathbf{a} x$-direction and $\mathbf{b} y$-direction. Measured data were extracted from the aerodynamic conductance $\left(g_{\mathrm{h}}\right)$ measurements along a wavy bare soil by McInnes et al. (1994) as $\delta=K_{\mathrm{a}} / \rho_{\mathrm{a}} c_{\mathrm{p}} g_{\mathrm{h}}$ with $K_{\mathrm{a}}(\mathrm{W} / \mathrm{mK}), \rho_{\mathrm{a}}\left(\mathrm{kg} / \mathrm{m}^{3}\right)$, and $c_{\mathrm{p}}(\mathrm{J} / \mathrm{kgK})$ the thermal conductivity, density, and specific heat capacity of air, respectively. The comparisons shown in $\mathbf{a}$ and $\mathbf{b}$ were obtained, respectively, for $\left(U_{\mathrm{a}}=4 \mathrm{~m} / \mathrm{s}, \alpha=2, \alpha_{\mathrm{s}}=3\right)$, and $\left(U_{\mathrm{a}}=3 \mathrm{~m} / \mathrm{s}, \alpha=2\right)$. For the condition that the wind direction is parallel to the ridge direction ( $y$-direction), airflow dynamics over the wavy surface is similar to that over a flat surface (no separation), so viscous sublayer thickness is constant along the surface and equals to $\delta_{x=0}$

similar behavior in aerodynamic conductance along a wavy bare soil surface. Additionally, we assume that $\alpha_{s}>\alpha$ in Eq. (4) refers to the shape parameter of the eddy distribution that forms the recirculating airflow within the separation zone. According to Haghighi and Or (2013), a turbulent regime characterized by a larger shape parameter $\alpha$ is dominated by larger eddies (with longer residence time) inducing a thicker viscous sublayer (relative to smaller-scale eddies) for a constant mean airflow velocity.

A comparison of the predicted variations in the viscous sublayer thickness [Eq. (4)] with the aerodynamic conductance data measured over a ridge-furrow bare soil by McInnes et al. (1994) is shown in Fig. 4. The results reveal that the overall pattern of the variations of the viscous sublayer thickness along the wavy surface (in $x$-direction) for two different wind directions perpendicular (Fig. 4a) and parallel (Fig. 4b) to the direction of ridges is represented reasonably well by the proposed model in Eq. (4). The thicker boundary layer observed (and predicted) above the separation zone implies a higher aerodynamic resistance to heat and mass fluxes (Schlünder 1988; Shahraeeni et al. 2012; Haghighi et al. 2013) and reaffirms the surface flux suppression beneath the separation region compared to the reattachment zone (Fig. 3) (McInnes et al. 1994; Wagner et al. 2011; Mirzaei et al. 2013).

\subsection{Local Evaporative Fluxes Along a Wavy Porous Surface}

Approximation of the wavy porous surface by equivalent localized aerodynamic and subsurface boundary conditions enables application of pore-scale model elements previously 
developed for flat evaporating porous surfaces (Shahraeeni et al. 2012; Haghighi et al. 2013; Haghighi and Or 2013). In the following, we describe the physical model that is schematically illustrated in Fig. 2.

\subsubsection{Resistances to Evaporative Fluxes from Porous Surfaces}

Lumped or equivalent resistances to scalar transport to/from land surfaces are often used to express various surface-atmosphere exchange processes. Specifically, water vapor transport from evaporating porous surfaces across the adjacent viscous sublayer is governed by molecular diffusion with resistances varying with boundary layer characteristics, surface water content, and soil type (Bange 1953; Cooke 1967; Schlünder 1988; Haghighi et al. 2013). Evaporation from drying porous surfaces (during stage-I) is quantified as a superposition of diffusion solutions from interacting pores supplied by viscous flow from a receding drying front. Haghighi et al. (2013) formulated a generalized top boundary condition for the effective resistance to evaporation considering $(1)$ a boundary layer resistance $\left(R_{\mathrm{BL}}\right)$ that accounts for nonlinear diffusive interactions between surface wetness (pore spacing) and the viscous sublayer thickness and (2) an internal capillary-viscous resistance $\left(R_{\mathrm{sv}}\right)$ to unsaturated capillary flow toward the surface that varies with saturation (Fig. 2). As the topsoil dries out, the internal viscous resistance to water supply from the drying front beneath an evaporating surface becomes dominant (Haghighi et al. 2013).

Considering the two resistances in series, evaporation flux, $E\left(\mathrm{~kg} / \mathrm{m}^{2} \mathrm{~s}\right)$, across the viscous sublayer is expressed (in the form of the Ohm's law) as (Haghighi et al. 2013)

$$
E(x / \lambda)=\frac{\Delta C}{R_{\mathrm{BL}}(x / \lambda)+R_{s v}(x / \lambda)}
$$

where $\Delta C=C_{\mathrm{s}}-C_{\mathrm{a}}\left(\mathrm{kg} / \mathrm{m}^{3}\right)$ is the water vapor concentration difference at an evaporating pore surface (assumed saturated at the surface temperature) and in the air above the viscous sublayer obtained from

$$
\Delta C=\frac{M_{\mathrm{w}}}{\Re}\left(\frac{P_{\mathrm{sat}}\left(T_{\mathrm{s}}\right)}{T_{\mathrm{s}}}-\mathrm{RH} \frac{P_{\mathrm{sat}}\left(T_{\mathrm{a}}\right)}{T_{\mathrm{a}}}\right)
$$

where, $M_{\mathrm{w}}(\mathrm{kg} / \mathrm{mol})$ is the molar mass of water $(0.018 \mathrm{~kg} / \mathrm{mol}), \Re(\mathrm{J} / \mathrm{mol} \mathrm{K})$ is the universal gas constant $(8.314 \mathrm{~J} / \mathrm{mol} \mathrm{K}), T_{\mathrm{s}}$, and $T_{\mathrm{a}}(\mathrm{K})$ are the surface and air temperatures, respectively, RH (-) is the air relative humidity, and $P_{\text {sat }}(\mathrm{Pa})$ is the vapor pressure at the liquid surface, assumed to be the saturation vapor pressure at the surface temperature (Hartmann 1994). Assuming a fully mixed turbulence above the viscous sublayer (Haghighi and Or 2013), we do not consider likely effects of atmospheric stability in this study (with small-scale laboratory-scale experiments) that are known to affect vapor concentration difference at large scales of interest (Haghighi and Or 2015b).

Considering dominant contribution of diffusion to evaporation from porous surfaces for a practical range of surface and airflow conditions, and availability of simple analytical diffusion solutions (Schlünder 1988), Haghighi et al. (2013) proposed simple and physically based analytical expressions for the boundary layer $\left(R_{\mathrm{BL}}\right)$ and internal capillary-viscous $\left(R_{\mathrm{Sv}}\right)$ resistances as functions of viscous sublayer thickness, surface water content, and mean (effective) pore size as

$$
\begin{aligned}
R_{\mathrm{BL}}(x / \lambda) & =\frac{\delta(x / \lambda)+r f\left(\theta_{\text {surf }}\right)}{D} \\
R_{\mathrm{Sv}}(x / \lambda) & =\frac{c_{4}}{K_{\text {eff }}\left(\theta_{\text {surf }}\right)}
\end{aligned}
$$


where $D\left(\mathrm{~m}^{2} / \mathrm{s}\right)$ is the water vapor diffusion coefficient in air $\left(\approx 2.5 \times 10^{-5} \mathrm{~m}^{2} / \mathrm{s}\right), r(\mathrm{~m})$ is the mean pore radius, $c_{4}=1.73 \times 10^{-5}(-)$ is a proportionality constant that reconciles units (considering SI units) for capillary liquid to vapor fluxes (Haghighi et al. 2013), $\theta_{\text {surf }}(-)$ is the surface water content, and $f\left(\theta_{\text {surf }}\right)$ is a surface wetness-dependent function obtained from the diffusion model of Schlünder (1988) as

$$
f\left(\theta_{\text {surf }}\right)=\frac{1}{\sqrt{\pi \theta_{\text {surf }}}}\left(\sqrt{\frac{\pi}{4 \theta_{\text {surf }}}}-1\right)
$$

This function accounts for the nonlinear diffusive interactions as the surface dries and spacing between remaining evaporating pores increases (Shahraeeni et al. 2012), and $K_{\text {eff }}=\chi K\left(\theta_{\text {surf }}\right)(\mathrm{m} / \mathrm{s})$ is the effective hydraulic conductivity of the unsaturated region (above the receding drying front). The coefficient $\chi(-)$ governs capillary flow between the drying front and the surface, and it ranges between 1 and 5 as the surface evolves from fully saturated to dry (Haghighi et al. 2013). The unsaturated hydraulic conductivity function $K\left(\theta_{\text {surf }}\right)$ is expressed as a function of surface water content as (Mualem 1976; van Genuchten 1980)

$$
K\left(\theta_{\text {surf }}\right)=K_{\mathrm{s}} \Theta_{\text {surf }}^{\tau}\left[1-\left(1-\Theta_{\text {surf }}^{1 /(1-1 / n)}\right)^{1-1 / n}\right]^{2}
$$

where $\Theta_{\text {surf }}=\frac{\theta_{\text {surf }}-\theta_{\mathrm{r}}}{\theta_{\mathrm{s}}-\theta_{\mathrm{r}}}$ is the effective surface water saturation with $\theta_{\mathrm{r}}(-)$ the residual water content, $\theta_{\mathrm{S}}(-)$ the saturated water content $(\approx$ sand porosity), $n(-)$ the pore size distribution index, $\tau(-)$ the tortuosity parameter related to flow path geometry and connectivity [generally set to 0.5 (Mualem 1976)], and $K_{\mathrm{S}}(\mathrm{m} / \mathrm{s})$ the saturated hydraulic conductivity. The coefficient $\chi=4$ has been used in this study, and numerical results have shown that this value represents a wide range of soil textures and surface water contents where internal capillary-viscous resistance affects transport (i.e., $\left.\Theta_{\text {surf }}<0.4\right)$ [see Fig. A1 in (Haghighi et al. 2013) for more details].

\subsubsection{Local Variations of Surface Water Content Along Wavy Porous Surfaces}

The surface water content is an important variable in Eqs. (7) to (10), and it may vary in time and space and must be determined for model closure. Considering the simple case of evaporation from a partially saturated porous medium supplied by a shallow water table, the surface water content is controlled by the drying front depth $H$ (m) (Fig. 1). We use the concept of the evaporative characteristic length $H_{\mathrm{C}}(\mathrm{m})$ (Lehmann et al. 2008) that determines the extent of the hydraulically connected region between a receding drying front and the evaporating surface. In the experimental part of this study, the "drying front" position is defined by a fixed shallow water table depth, and the water content distribution to the surface follows a quasi-hydrostatic profile (Shokri et al. 2008). Keeping a water table (or drying front) depth shorter than the evaporative characteristic length for the porous medium $\left(H \leq H_{\mathrm{C}}\right)$ enables an expression of the hydraulically connected surface water content as (Lehmann et al. 2008; Aminzadeh and Or 2013)

$$
\frac{\theta_{\text {surf }}(x / \lambda)}{\theta_{\mathrm{s}}}=1-\left(1-\frac{\theta_{\mathrm{r}}}{\theta_{\mathrm{s}}}\right) \frac{H}{H_{C}}
$$

where $H(\mathrm{~m})$ is the drying front depth, that for a wavy surface is obtained from

$$
H(x / \lambda)=\gamma\left(1+\cos \left(2 \pi \frac{x}{\lambda}\right)\right)+Z_{T}
$$


where $Z_{\mathrm{T}}=H_{\mathrm{wt}}-2 \gamma(\mathrm{m})$ is the height of the trough above the shallow water table (Fig. 1) with $H_{\mathrm{wt}}(\mathrm{m})$ the depth of the water table measured from ridges (see Fig. 1); and $H_{\mathrm{C}}(\mathrm{m})$ is the evaporative characteristic length that determines the deepest water table position before hydraulic connectivity with the evaporating surface above is lost (termed here "surface decoupling"). Following Lehmann et al. (2008), we can introduce the role of viscous resistance that is proportional to surface water content and potential evaporation rate resulting in an effective characteristic length expressed as

$$
H_{\mathrm{C}}(x / \lambda)=\frac{H_{\mathrm{G}}}{1+\frac{E^{\mathrm{o}}}{\rho K_{\text {eff }}\left(\theta_{\text {surf }}\right)}}
$$

where $H_{\mathrm{G}}(\mathrm{m})$ is the gravity characteristic length ranging from 90 to $150 \mathrm{~mm}$ for coarse- and fine-textured sand media (Lehmann et al. 2008), $\rho\left(\mathrm{kg} / \mathrm{m}^{3}\right)$ the water density $\left(\approx 1000 \mathrm{~kg} / \mathrm{m}^{3}\right)$, and $E^{o}\left(\mathrm{~kg} / \mathrm{m}^{2} \mathrm{~s}\right)$ is the potential evaporation flux from a free water surface under similar conditions (providing an upper bound for viscous resistances) that could be estimated from

$$
E^{o}(x / \lambda)=D \frac{\Delta C}{\delta(x / \lambda)}
$$

For given local variations of surface and aerodynamic properties along a wavy surface, Eqs. (11) to (14) are solved to estimate local variations of evaporative characteristic length and surface water content along the wavy surface. Note that for fully saturated conditions, $H(x / \lambda)=0$ everywhere below the wavy surface and thus $\theta_{\text {surf }}(x / \lambda)=\theta_{\mathrm{s}}[$ Eq. (11)].

\subsection{Mean Evaporation Flux and Rate from Wavy Porous Surfaces}

Combining Eqs. (4) to (14), we obtain the mean evaporation flux, $\bar{E}\left(\mathrm{~kg} / \mathrm{m}^{2} \mathrm{~s}\right)$, from the wavy surface representative element (Figs. 1,2) as

$$
\bar{E}=\frac{\Delta C}{\lambda} \int_{0}^{\lambda} \frac{\mathrm{d} x}{R_{\mathrm{BL}}(x / \lambda)+R_{\mathrm{sv}}(x / \lambda)}
$$

where $R_{\mathrm{BL}}(x / \lambda)$ and $R_{\mathrm{Sv}}(x / \lambda)$ are defined in Eqs. (7) and (8), respectively. Numerical evaluation of Eq. (15) using the Simpson's rule yields the mean evaporation flux from wavy porous surfaces as a function of surface geometry $(\gamma$ and $\lambda$ ) whose influences on external aerodynamic and internal porous medium properties (and accordingly on evaporative fluxes) are embedded in $R_{\mathrm{BL}}$ and $R_{\mathrm{Sv}}$, respectively.

In addition to the estimation of the mean evaporation flux, mean evaporation rate from a representative element of the wavy surface, $e_{\mathrm{b}}(\mathrm{kg} / \mathrm{s})$, is given as

$$
e_{\mathrm{b}}=\bar{E} \cdot A_{\mathrm{b}}
$$

where $A_{\mathrm{b}}=w \times s\left(\mathrm{~m}^{2}\right)$ is the surface area of the wavy building block with the width $w(\mathrm{~m})$ and the length $s(\mathrm{~m})$ given according to

$$
s=\int_{0}^{\lambda} \sqrt{1+\left(\frac{2 \pi \gamma}{\lambda} \sin \left(\frac{2 \pi}{\lambda} x\right)\right)^{2}} d x
$$

Note that the total mean evaporation rate, $\bar{e}(\mathrm{~kg} / \mathrm{s})$, from an evaporating system composed of $N_{\mathrm{b}}$ wavy surface building blocks is simply

$$
\bar{e}=e_{\mathrm{b}} \cdot N_{\mathrm{b}}
$$

where $N_{\mathrm{b}}=\ell / \lambda$ with $\ell(\mathrm{m})$ the length of the system. 


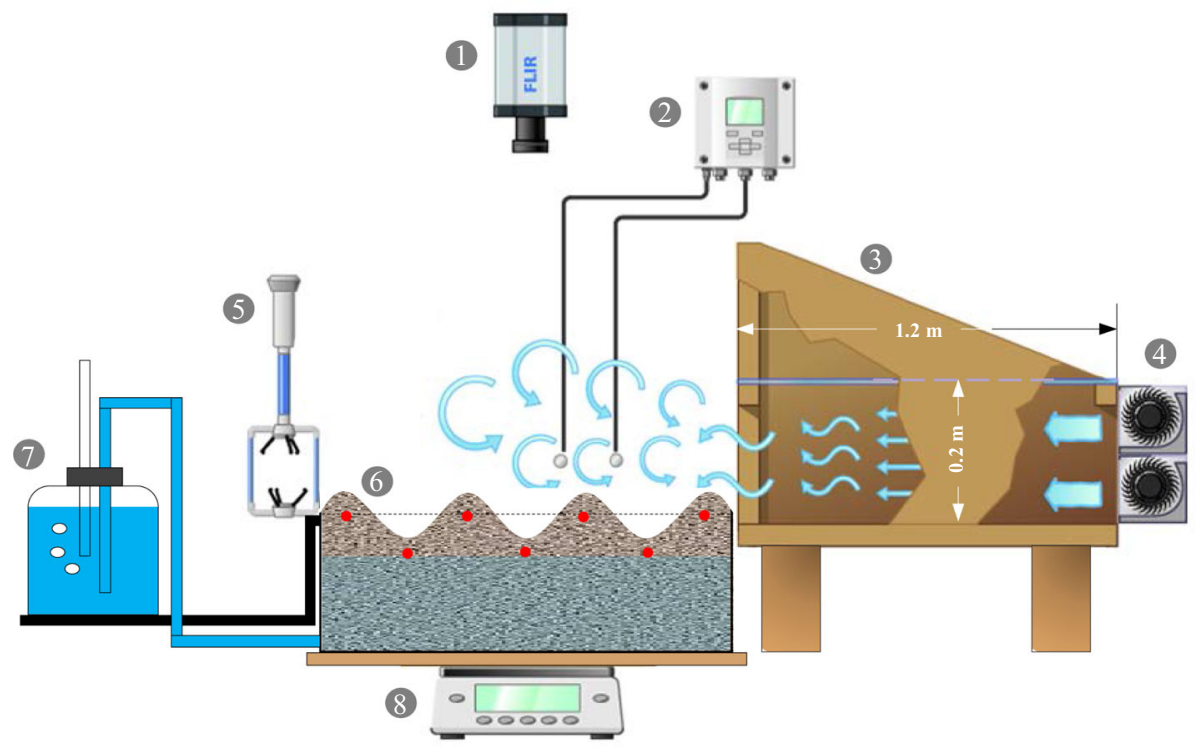

Fig. 5 Experimental setup used to study evaporation from wavy sand surfaces into prescribed turbulent airflow regimes: 1 infrared camera; 2 logger for single point (and low frequency) measurement of ambient temperature, velocity, and relative humidity in the middle of the duct tunnel above the test surface; 3 wind production chamber; 4 blowing fans; 5 high-frequency 3D ultrasonic anemometer recording near-surface air velocity field at $30 \mathrm{~Hz} ; 6$ a sand-filled box $(1.0 \times 1.0 \times 0.3 \mathrm{~m})$ with particle sizes ranging from 0.3 to $0.9 \mathrm{~mm}$ and porosity of $0.4 ; 7$ Mariotte bottle that adjusts water table depth in the soil sample; and 8 balance. The location of TDR probes monitoring and recording spatio-temporal variations of surface water content is marked by red dots on the sand sample. The dashed line indicates a corresponding flat evaporating sand surface

\section{Experimental Setup for Turbulent Evaporation from Wavy Sand Surfaces}

The proposed model was tested using evaporation experiments conducted under controlled boundary conditions in a small wind tunnel $(\mathrm{L} \times \mathrm{W} \times \mathrm{H}: 1.2 \times 1.2 \times 0.2 \mathrm{~m}$; see Fig. 5). The wind tunnel was equipped with four blowing fans with built-in straightener grids (TAR/L, LTG Inc., Germany) providing stable airflows over the evaporating surface $\left(4 \times 1040 \mathrm{~m}^{3} / \mathrm{h}\right.$ @ 1050 rpm). A schematic of the experimental setup is illustrated in Fig. 5.

A sand-filled box $(1.0 \times 1.0 \times 0.3 \mathrm{~m})$ with particle sizes ranging from 0.3 to $0.9 \mathrm{~mm}\left[\theta_{\mathrm{s}}=\right.$ 0.4 and $n=2.7$ (Leij et al. 1999)] was used as the evaporating medium. The sand surface was shaped by sinusoidal wavy molds with prescribed amplitudes $(2 \gamma)$ and wavelengths $(\lambda)$. A series of drying experiments were performed for four wavy surface configurations $(2 \gamma, \lambda)$ : $(50,200),(50,100),(100,200)$, and $(100,100) \mathrm{mm}$ with different number of replicates as 7 , 7,5 , and 3 runs, respectively. The sand box was connected to a Mariotte bottle for maintaining a constant water table depth below the surface and thus enabling control and maintenance of constant surface water content (determined based on the depth of the water table and water retention characteristics of the sand). The gravity characteristic length $\left(H_{\mathrm{G}}\right)$ for this sand was approximately $130 \mathrm{~mm}$ based on Lehmann et al.'s (2008) approximation. The nearsurface water content (water content of the top $0-5 \mathrm{~mm}$ soil layer) at different locations below ridges and troughs along wavy sand surfaces was measured and recorded by time domain reflectometry (TDR) method (TDR100, Campbell Scientific Inc., UT, USA). 
The temperature field at the surface was resolved using an IR imager sampling at $30 \mathrm{~Hz}$. We have used an IR thermal camera (FLIR SC6000, FLIR Systems, MA, USA) with a noise equivalent temperature difference of $35 \mathrm{mK} @ 30^{\circ} \mathrm{C}$. The IR imager is equipped with a quantum well infrared photon (QWIP) detector capable of recording infrared radiation in a narrow range of wavelength of 8.0-9.2 micron at high resolution $(640 \times 512$ pixels $)$. The integration time of the detector is $10 \mathrm{~ms}$, and it is equipped with a linear Stirling cooler. The thermal images were converted to the surface temperature assuming a constant surface emissivity of 0.95 (Mira et al. 2007). The acquired images are transferred to a dedicated PC with ThermaCAM Researcher software (FLIR Systems, MA, USA) for subsequent analyses.

Details of the velocity of an air layer of $50 \mathrm{~mm}$ thickness adjacent to the surface $\left(U_{\mathrm{a}}\right)$ was recorded at the edge of the evaporating surface using a 3D ultrasonic anemometer with $0.01 \mathrm{~m} / \mathrm{s}$ accuracy (WindMaster, Gill Instruments Ltd., The Netherland) acquiring measurements at $30 \mathrm{~Hz}$. The temperature and relative humidity of the ambient were monitored at a distance of $100 \mathrm{~mm}$ above the test surface (in the middle of the duct tunnel) using a temperature and humidity transmitter (HMT337, Vaisala HUMICAP ${ }^{\circledR}$, Finland). Evaporative mass loss from the soil sample was measured using a heavy duty floor balance equipped with four beam load cells (H8C-Cx-250kg-4B, Zemic, Netherlands) with an accuracy of $\leq \pm 0.023 \%$ (which implies a water mass loss accuracy of $\pm 1 \mathrm{~kg}$ ) and monitored by a controlling unit (PS Plus, Swiss Waagen, Switzerland).

\section{Results and Discussion}

We first report the performance of the proposed model to describe localized external and internal boundary conditions and associated localized evaporative fluxes under prescribed turbulent regimes using surface temperature field resolved by IRT. Next, we present the contribution of subsurface hydraulic properties and aerodynamic boundary layer to localized fluxes, and finally integrate the results and compare model predictions for mean evaporative fluxes and rates with mass loss measurements.

\subsection{Localized Evaporative Fluxes}

\subsubsection{Thermal Manifestation of Localized Evaporative Fluxes}

The temperature of an evaporating surface contains information on the partitioning of available energy among various components (i.e., sensible, latent, and conductive heat fluxes, and net radiation) and reflects their relative contribution (Kalma et al. 2008; Qiu and Zhao 2010; Haghighi and Or 2015a). In the absence of incoming short-wave radiation (as in the laboratory experiments reported here), the temperature of an evaporating surface is generally lower than that of the flowing air (Shahraeeni and Or 2010; Haghighi and Or 2015a). Consequently, hot and cold regions on an evaporating surface (obtained by IRT measurements) are indicative of regions with relatively low and high evaporation rates, respectively (Shahraeeni and Or 2010; Aminzadeh and Or 2013).

The pattern of surface temperature thus enables qualitative (and simple quantitative) inferences on interactions between surface geometry, medium water flow properties, and airflow boundary layer that affect "local" evaporative fluxes. Spatially resolved snapshots of surface temperature $5 \mathrm{~h}$ after initiation of the evaporation test for flat and wavy sand surfaces under low and high wind speed conditions are depicted in Fig. 6. The images depict the spatial distribution of surface temperature field over a footprint of $500 \times 500 \mathrm{~mm}$ in the center of 
the $1000 \times 1000 \mathrm{~mm}$ test surface. The warm and cool stripes observed in the IR images show evaporation signatures from ridges and troughs suggesting that the relative contributions to mean surface evaporation under low wind speed from these two regions were similar. For high airflow, the troughs were cooler and support high evaporative fluxes for all wavy surface configurations in this study (more noticeable for the large amplitude and high aspect ratio waves).

The dynamics of the temperature fields along the center of the image (shown as the vertical dashed line on the IR snapshot of the flat surface in Fig. 6) are presented in Fig. 7. The IR snapshots shown in Fig. 7 clearly illustrate that for low wind speeds, the ridge and trough surfaces remained connected to the water table during the entire experiment. For high wind velocity, however, ridge surfaces became hydraulically decoupled from water table below and the surface dried out after $15 \mathrm{~h}$ of exposure (no longer contributing significantly to surface evaporation).

\subsubsection{Localized Internal and External Boundary Conditions}

The interactions between internal soil transport processes and external (atmospheric) conditions that shape the observed spatio-temporal surface temperature patterns were simulated by the proposed model. Evaporation from sandy wavy surfaces using prescribed surface and aerodynamic conditions $\left(r=0.1 \mathrm{~mm}, \theta_{\mathrm{s}}=0.4, \theta_{\mathrm{r}} / \theta_{\mathrm{s}}=0.05, H_{\mathrm{G}}=130 \mathrm{~mm}, T_{\mathrm{s}}=289 \mathrm{~K}\right.$, $T_{\mathrm{a}}=296 \mathrm{~K}, \mathrm{RH}=40 \%, U_{\mathrm{a}}=0.7$ and $3.5 \mathrm{~m} / \mathrm{s}$, and $H_{\mathrm{wt}}=100 \mathrm{~mm}$ ) were modeled for the first $15 \mathrm{~h}$ of the experiments, while the drying front or water table depth below the ridges did not exceed the evaporative characteristic length of the sand (i.e., the ridge surface remained connected to the water table below).

Figure 8 shows model predictions of local variations of internal $\left(\theta_{\text {surf }}\right)$ and external $(\delta)$ boundary conditions as well as corresponding evaporative fluxes along low $(2 \gamma=50 \mathrm{~mm})$ and high $(2 \gamma=100 \mathrm{~mm})$ surface amplitudes subjected to low $(0.7 \mathrm{~m} / \mathrm{s}$, blue solid lines $)$ and high $(3.5 \mathrm{~m} / \mathrm{s}$, red dashed lines) wind speeds. We note that rapid IR measurements of surface thermal fluctuations over troughs and ridges in conjunction with concepts from the SR theory enabled estimation of eddy spectrum shape parameter as $\alpha_{\mathrm{s}}=3$ and $\alpha=2$ for separation and reattachment zones, respectively, that are required for quantifying viscous sublayer thickness and associated surface fluxes [see (Haghighi and Or 2015a) for more details]. The higher evaporative fluxes from the ridges for the two wavy surfaces under the low wind speed condition were captured by the physical model [Eq. (5)]. For high wind speeds, however, the pattern varies, and evaporative fluxes from the troughs are higher with differences between evaporative fluxes from ridges and troughs more noticeable relative to the low wind condition (very similar to surface thermal patterns shown in Fig. 6).

The measured and predicted variations in surface water content show a decrease in surface water content below ridges (of both low- and high-amplitude waves) for high wind velocity. Such reduction in surface water content may reflect internal viscous resistance that impacts the ridges stronger due to (1) longer capillary paths from water table; (2) lower initial surface water contents; and (3) higher initial evaporation rates (relative to the troughs). Note that a subtle change in surface wetness for surface water contents lower than 0.1 (i.e., $\theta_{\text {surf }} \approx \theta_{\mathrm{r}}$ ) may significantly increase the internal viscous resistance [Eq. (8)] and result in a considerable decrease in local evaporative fluxes (Haghighi et al. 2013). The high initial evaporation rates from ridges due to a thinner boundary layer thickness (thinner for high wind speed relative to the low wind speed condition) shorten the evaporative characteristic length and may induce early surface decoupling (see Sect. 2.2.2). The capillary decoupling reduces the relative contribution of ridges to surface evaporative fluxes despite favorable (thinner) low boundary 


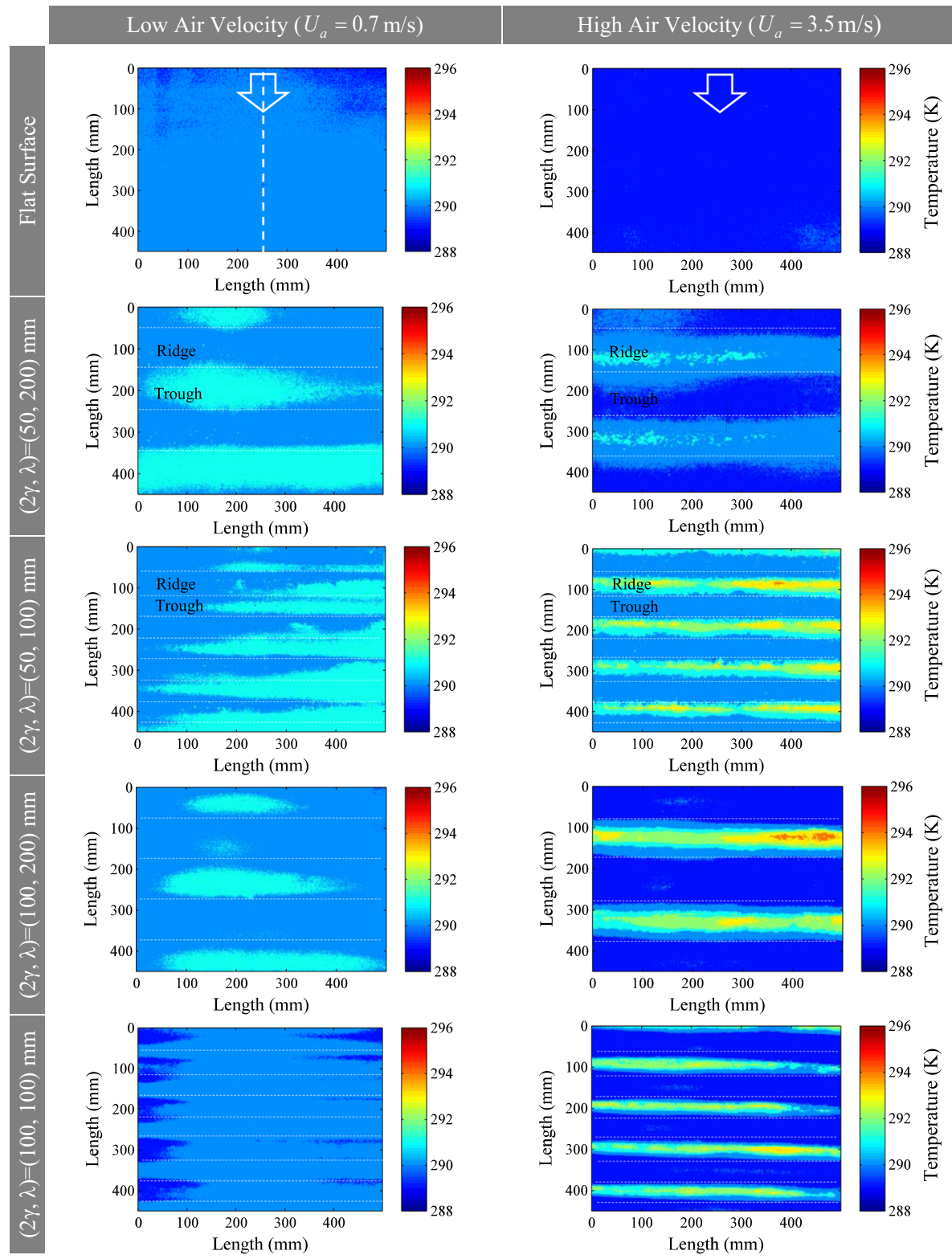

Fig. 6 Spatially resolved snapshots of surface temperature at time $5 \mathrm{~h}$ (from the onset of evaporation tests) during flat and wavy sand drying under low and high wind speeds with $T_{\mathrm{a}}=296 \mathrm{~K}$ and $\mathrm{RH}=40 \%$. Arrows indicate the direction of wind velocity perpendicular to the ridges

layer resistance. Hence, for high wind speeds, evaporation from troughs control evaporation as observed in surface temperature snapshots (Figs. 6, 7) and predicted by the physical model (Fig. 8).

In addition to the physical model predictions, we quantified spatial distribution of evaporative fluxes using the relatively simple 3T model of Qiu and Zhao (2010, Eq. (10) (as a 


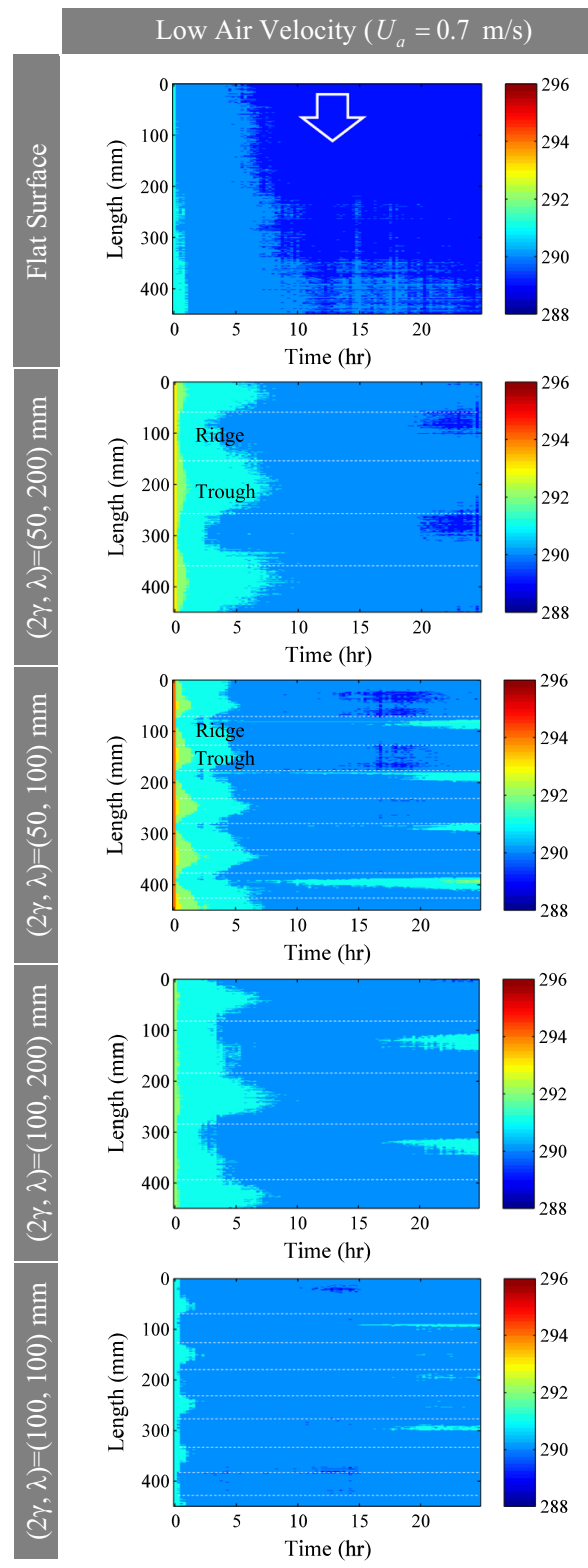

High Air Velocity $\left(U_{a}=3.5 \mathrm{~m} / \mathrm{s}\right)$
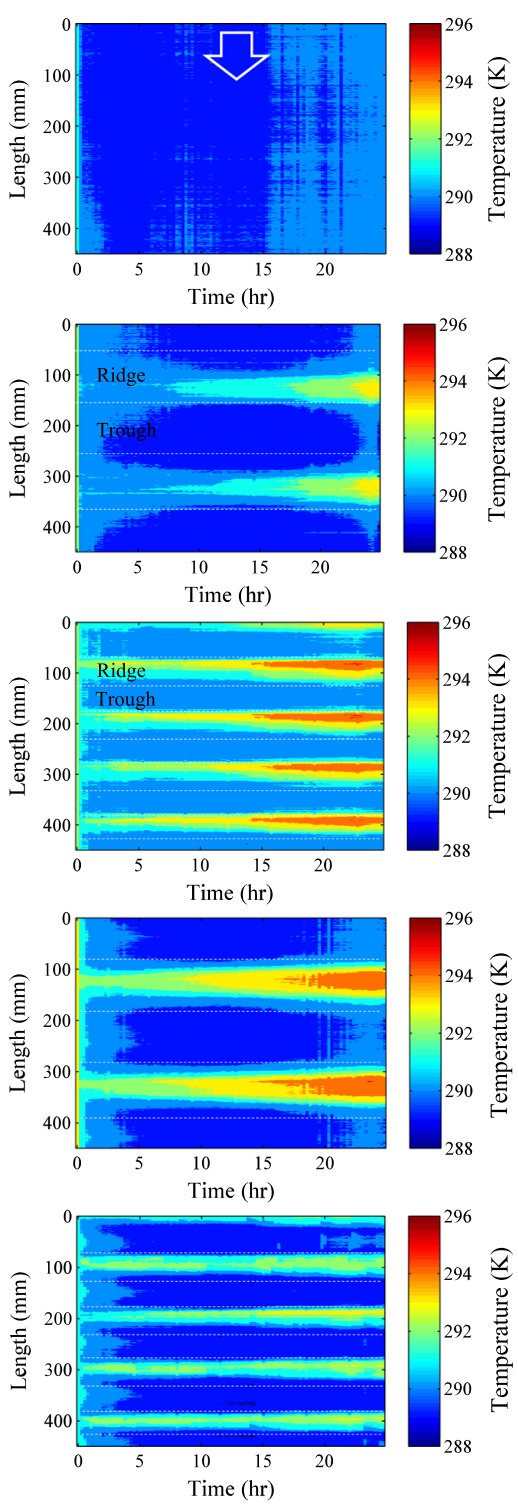

Fig. 7 Temporal evolution of surface temperature along the centerline (the vertical dashed line shown in Fig. 6) recorded during flat and wavy sand drying under low and high wind speeds with $T_{\mathrm{a}}=296 \mathrm{~K}$ and $\mathrm{RH}=40 \%$

"diagnostic" tool to integrate local evaporative fluxes and surface temperature information). Using information on air temperature, and wet and dry soil temperatures, the 3T model links surface thermal measurement with surface soil water content and estimates surface evaporation rates (Qiu et al. 1998). The spatial distributions of surface evaporative fluxes shown in Fig. 8 confirm the results obtained by the physical model regarding relative contribution of 

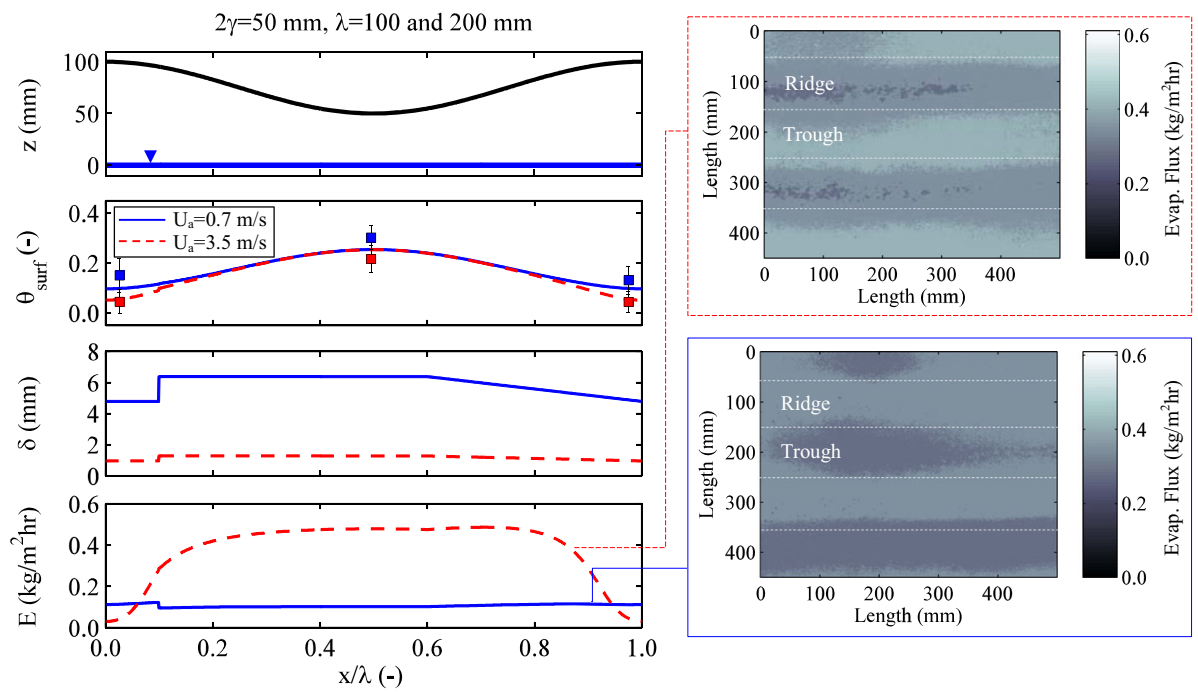

$2 \gamma=100 \mathrm{~mm}, \lambda=100$ and $200 \mathrm{~mm}$
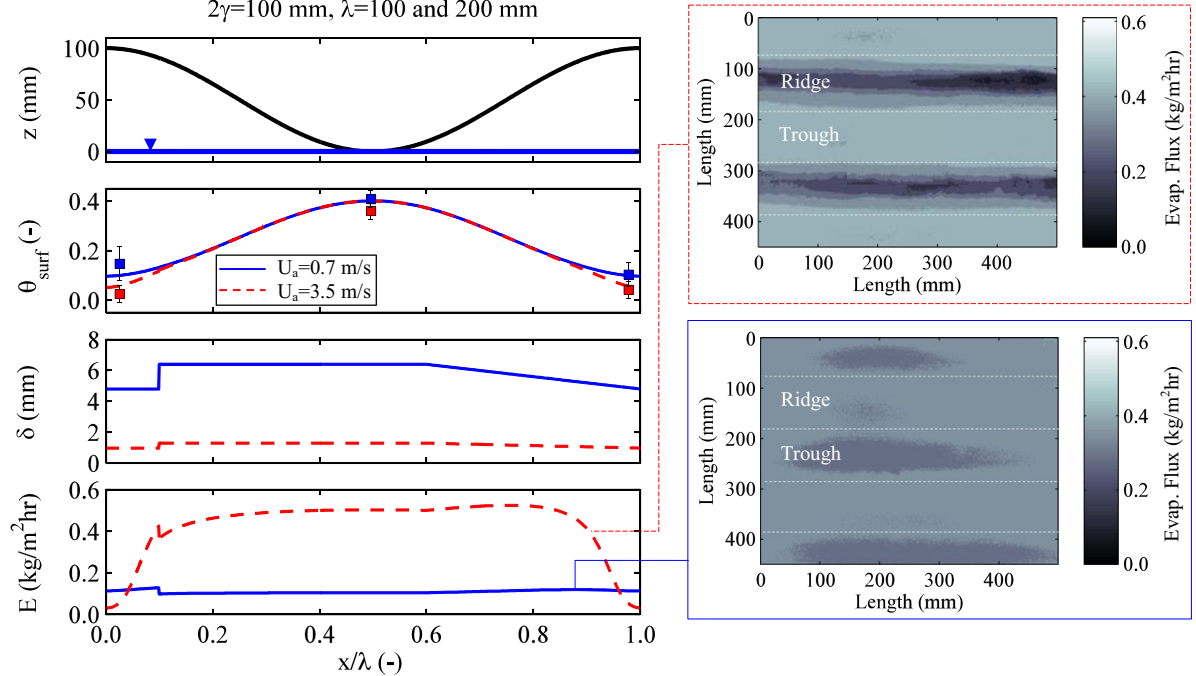

Fig. 8 Predicted local variations in internal $\left(\theta_{\text {surf }}\right)$ and external $(\delta)$ boundary conditions as well as corresponding localized evaporative fluxes along low $(2 \gamma=50 \mathrm{~mm})$ and high $(2 \gamma=100 \mathrm{~mm})$ amplitude wavy sand surfaces under low $(0.7 \mathrm{~m} / \mathrm{s}$, blue solid lines $)$ and high $(3.5 \mathrm{~m} / \mathrm{s}$, red dashed lines $)$ wind speeds based on the prescribed aerodynamic and surface properties during the first $15 \mathrm{~h}$ of the experiments (before complete decoupling of ridges from the water table below). Square symbols indicate surface water content values measured beneath ridges and troughs using TDR probes. Diagnostic predictions of surface evaporative fluxes (spatial distributions) were obtained from the 3T model of Qiu and Zhao (2010) based on the surface temperature snapshots presented in Fig. 6 to provide an estimate of local (spatial) variations of surface evaporative fluxes

ridges and troughs to surface evaporation in the presence of a shallow water table (surface averaged evaporation rates predicted by the $3 \mathrm{~T}$ model are presented in Table 1).

Note that the results in Fig. 8 presented as a function of $x / \lambda$ (rather than $x$ ) suggest that the magnitude of local evaporative fluxes predicted by the physical model are independent of the 
Table 1 Measured and predicted mean evaporation rate data

\begin{tabular}{|c|c|c|c|c|c|c|}
\hline & \multirow[t]{2}{*}{$U_{a}(\mathrm{~m} / \mathrm{s})$} & \multicolumn{5}{|c|}{ Mean evaporation rate $(\mathrm{kg} / \mathrm{h})$} \\
\hline & & Flat & $(50,200)$ & $(50,100)$ & $(100,200)$ & $(100,100)$ \\
\hline \multirow[t]{3}{*}{ Experiment* } & 0.7 & 0.12 & $0.11(0.14)$ & $0.14(0.12)$ & $0.14(0.15)$ & $0.20(0.15)$ \\
\hline & 1.8 & 0.35 & $0.29(0.12)$ & $0.37(0.12)$ & $0.30(0.06)$ & $0.55(0.20)$ \\
\hline & 3.5 & 0.78 & $0.50(0.17)$ & $0.61(0.17)$ & $0.70(0.18)$ & $1.01(0.22)$ \\
\hline \multirow[t]{3}{*}{ 3T model } & 0.7 & 0.16 & 0.13 & 0.17 & 0.16 & 0.25 \\
\hline & 1.8 & 0.41 & 0.35 & 0.50 & 0.33 & 0.63 \\
\hline & 3.5 & 0.84 & 0.52 & 0.66 & 0.69 & 1.11 \\
\hline \multirow[t]{3}{*}{ Physical model } & 0.7 & 0.14 & 0.12 & 0.16 & 0.16 & 0.25 \\
\hline & 1.8 & 0.35 & 0.27 & 0.35 & 0.37 & 0.58 \\
\hline & 3.5 & 0.66 & 0.44 & 0.56 & 0.63 & 0.99 \\
\hline
\end{tabular}

* Values in parenthesis indicate standard deviation of measurements: 7 runs for $(50,200)$ and $(50,100), 5$ runs for $(100,200)$, and 3 runs for $(100,100)$

wavy surface wavelength $(\lambda)$; thus, the results are applicable for wavy surface configurations of the same amplitude (e.g., $(2 \gamma, \lambda)=(50,200)$ and $(50,100) \mathrm{mm})$. Nevertheless, the surface temperature field of the high aspect ratio surface $(50,100)$ exhibited a higher temperature difference between ridges and troughs under high wind speed $(3.5 \mathrm{~m} / \mathrm{s})$ that may imply a marginal difference in the pattern of local evaporative fluxes from the low and high aspect ratio surfaces under high wind speed condition. Nevertheless, we note that this observation of warmer ridges of the steeper wavy surface (relative to the low aspect ratio surface) under high wind speed condition that are manifested in the IR snapshots could be accounted for by lateral heat exchange of pores of different evaporative fluxes due to local variations of the viscous sublayer thickness as a function of $x$ (rather than $x / \lambda$ ), and by capillary coupling signature with the water table below.

\subsection{Mean Evaporation Fluxes and Mass Loss Rates}

Evaluating Eqs. (15) and (18) for mean evaporation flux $\bar{E}\left(\mathrm{~kg} / \mathrm{m}^{2} \mathrm{~s}\right)$ and mass loss rate $\bar{e}$ $(\mathrm{kg} / \mathrm{s})$ from wavy sand surfaces (considering measured mass loss data obtained during the first $15 \mathrm{~h}$ of the evaporation experiments), we compared model predictions with experimental data (Fig. 9). The evaporation rate represents cumulative amount of water withdrawn from the system within a specific time (this metric is scale dependent), whereas the evaporation flux is the measure of average evaporation rate per unit evaporating surface area (scale independent). Thus, experimentally determined mean evaporation rates $(\bar{e})$ were extracted directly from weighing mass loss from the evaporating sand samples, and the corresponding mean evaporation fluxes $(\bar{E})$ were obtained using the total surface area exposed to airflow (i.e., $\bar{E}=\bar{e} /(w \times s))$. Note that the ratio of evaporating wavy surface area to the corresponding flat-surface area $\left(A_{\text {wavy }} / A_{\text {flat }}\right.$ with $\left.A_{\text {flat }}=1 \mathrm{~m}^{2}\right)$ varied in this study from 1.14 to 2.30 for wavy surfaces with $(2 \gamma, \lambda)=(50,200)$ and $(100,100) \mathrm{mm}$, respectively.

The results shown in Fig. 9 reveal that the overall pattern of the variations in measured evaporation fluxes and mass loss rates were described reasonably well by the physical model (absolute mass loss rates are given in Table 1). These results also reveal that evaporative fluxes from wavy porous surfaces underlain by a shallow water table are reduced compared to the corresponding flat surface (the ratios are less than unity). This interesting result is 


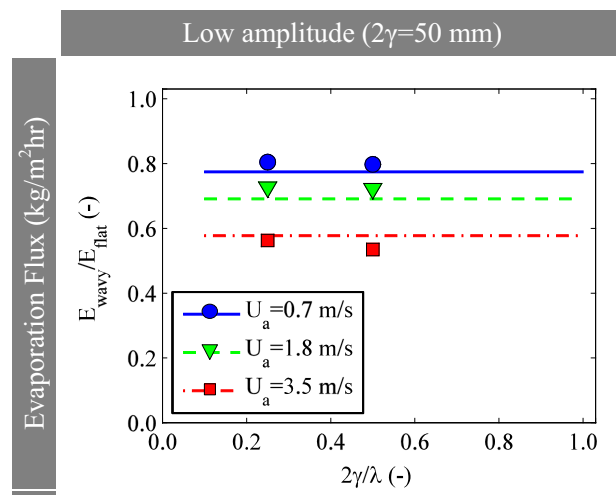

High amplitude $(2 \gamma=100 \mathrm{~mm})$
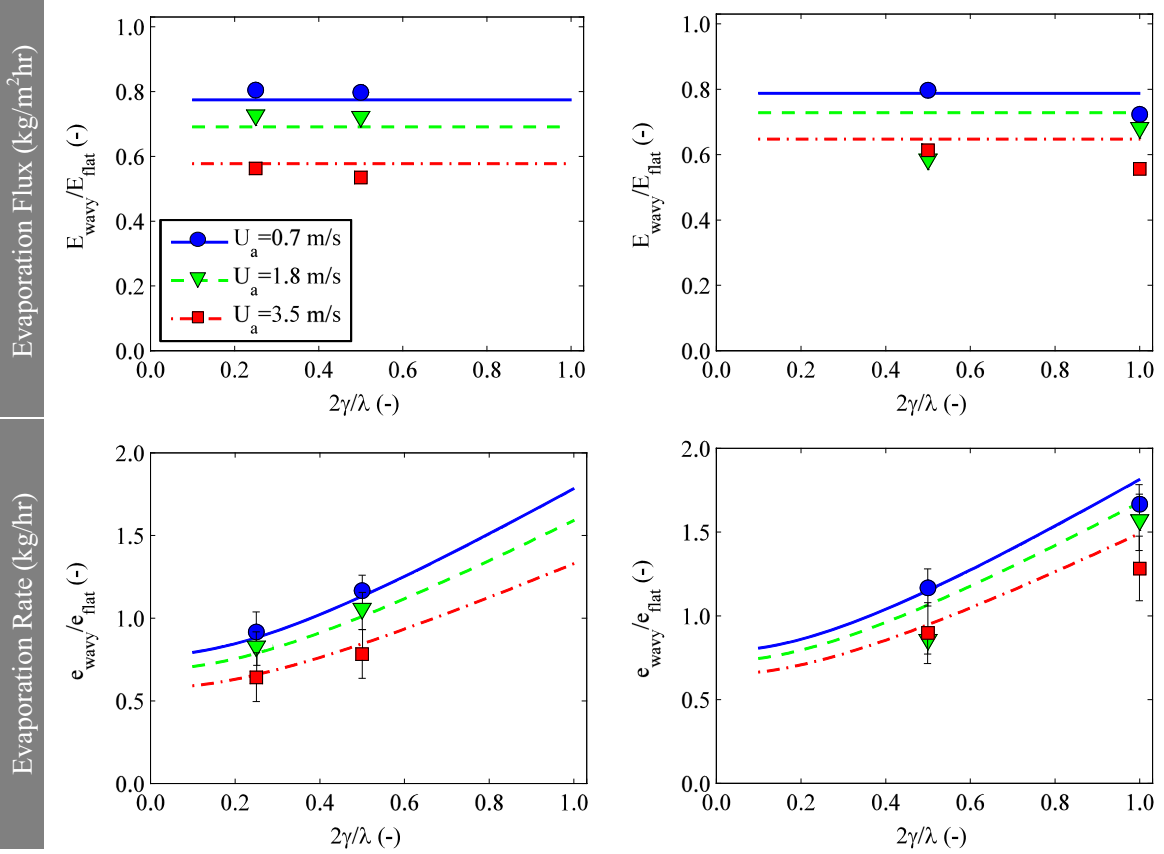

Fig. 9 Predicted (lines) and measured (symbols) mean evaporation flux and rate ratios from low- and highamplitude wavy sand surfaces (relative to flat surface) under different wind velocities. Error bars represent standard deviation of measured mass loss rates from wavy sand surfaces with different number of replicates: 7 runs for $\mathrm{AR}=0.25$ and 0.5 (low amplitude), 5 runs for $\mathrm{AR}=0.5$ (high amplitude), and 3 runs for $\mathrm{AR}=1.0$ (see also Table 1). We note that the evaporation flux is scaled per unit area and expresses mass loss per unit surface area (increased surface area due to waviness is scaled out), and the evaporation rate is the mass loss per unit projected area (waviness increases evaporating area relative to a flat surface)

explained by the double effect of evaporative flux suppression from the troughs with a thicker boundary layer, and the reduction in the evaporative flux from the ridges due to hydraulic decoupling. Hence, despite a considerably larger evaporating wavy surface area, evaporation flux is reduced relative to the flat surface. Considering the sensitivity of the evaporative characteristic length to local viscous resistance [enhanced by wind velocity—see Eqs. (13) and (14)], the hydraulic decoupling of ridges is enhanced with increasing the wind velocity and the evaporative flux ratio decreases (the absolute mass loss for wavy to flat surfaces-see Table 1). Furthermore, the observed and predicted results exhibited insensitivity of the flux ratios to the aspect ratio of the surface (for both low and high amplitudes), suggesting that the evaporation rate (mass loss from the same overall surface footprint) was increased in proportion to increasing surface area with increasing aspect ratio.

In addition to flux ratios, measurements and model predictions depicted in Fig. 9 show that evaporation rates from wavy surfaces may be enhanced or suppressed relative to a similar flat surface (the absolute mass loss values are given in Table 1). The enhanced evaporative water loss at high aspect ratios is associated with larger evaporating surfaces, especially under low wind speed condition where hydraulic coupling with the water table (or the receding drying front in natural systems) is maintained for both low- and high-amplitude wavy surface configurations used in this study. The lower evaporation rate ratios at low aspect ratio surfaces 
(even for low wind velocity) reflect the dominance of flux suppression in the detachment region for which the mild increase in total evaporating area is not sufficient to compensate relative to a saturated flat surface.

The hydraulic decoupling for both low- and high-amplitude wavy surfaces under high wind velocity (relative to the evaporative characteristic length) overwhelms the overall wavy surface evaporative response for a wide range of aspect ratios that remain below the values for an equivalent flat surface. While model predictions capture the trend quite well for low aspect ratio waves, the model marginally overpredicts the ratios for higher aspect ratios $(2 \gamma / \lambda=1)$, especially under high wind speeds probably due to earlier hydraulic decoupling (shorter effective characteristic length) promoted by the initially lower water content over the ridges and the enhanced viscous losses due to higher fluxes at the ridges (high viscous resistance).

\section{Summary and Conclusions}

We developed a physically based model that explicitly accounts for key variables that influence evaporation rates from wavy porous surfaces. The pore-scale surface resistance model of Haghighi et al. (2013), coupled with concepts from fluid flow dynamics over wavy and hilly solid surfaces and SR theory, was extended by incorporating interactions with wavy surfaces resulting in localization of viscous sublayer thickness. The model also considers subsurface interactions that affect surface water content and capillary flows toward the evaporating wavy surface. The localization of boundary layer interactions and subsurface coupling developed here provides a simple theoretical framework for considering evaporation rates and fluxes from bare tilled soil surfaces. Evaporation rate is defined as mass loss per unit projected area (waviness increases evaporating area relative to a flat surface), while the evaporation flux is scaled per unit area and expresses the mass loss per unit surface area (increased surface area due to waviness is scaled out).

Considering localization of mean viscous sublayer thickness and its effects on the resulting hydraulic soil behavior, the model accounts for local evaporative fluxes manifested in the surface temperature field of the controlled laboratory drying experiments of wavy sand surfaces in the presence of a shallow water table. The interplay of localized internal (surface water content) and external (viscous sublayer thickness) boundary conditions and associated localized evaporative fluxes were in good agreement with TDR measurements, literature data (McInnes et al. 1994), and diagnostic predictions by the 3T model (Qiu and Zhao 2010). The model predictions highlight the significant subsurface coupling and internal viscous resistance to localized evaporative fluxes where low wind speeds could prolong (and conversely for high wind speeds) the contribution of evaporating ridges to surface mean evaporation rates.

Furthermore, model predictions of mean evaporation rates and surface fluxes were in good agreement with experimental results obtained by direct mass loss measurements of the evaporating surface. The results revealed that the relative evaporative mass loss (per saturated flat-surface evaporation) increases with increasing surface aspect ratio (i.e., increasing exposure surface area) and with lower wind velocity (lower viscous resistance below ridges). The same ratio was reduced by increasing wind velocity and by decreasing surface aspect ratio, indicating that increased exposure surface area does not compensate suppressed fluxes over the various regions (troughs with thicker boundary layer and ridges' decoupling from water table below due to enhanced viscous effects).

The model requires additional tests to assess its applicability to natural surfaces at the field-scale; nevertheless, the simple framework offers a means for systematic evaluation of 
key surface and aerodynamic parameters that affect evaporative fluxes from wavy porous surfaces into turbulent airflows. The model may also be useful for studying evaporation from wavy plant leaves and designing efficient evaporative drying scenarios for certain industrial purposes (e.g., wood and building materials drying). The approach could provide a building block for upscaling evaporation predictions to landscape-scale applications with incorporation of shortwave radiation and associated geometrical interactions that would enhance localization of surface energy balance components in addition to the localized effects presented here.

Acknowledgments The authors thank three reviewers for their insightful comments that helped improve the manuscript. The funding by the Swiss National Science Foundation of the project "Evaporation from terrestrial surfaces_linking pore scale phenomena with landscape processes" (200021-113442) and the financial support of the German Research Foundation DFG of the project "Multi-Scale Interfaces in Unsaturated Soil" (MUSIS; FOR 1083) are gratefully acknowledged. Technical assistance of Daniel Breitenstein and Hans Wunderli (ETH Zurich) is greatly appreciated.

\section{References}

Allmaras, R.R., Nelson, W.W., Hallauer, E.A.: Fall versus spring plowing and related heat balance in western corn belt. Minn. Agric. Exp. Stn. Tech. Bull. 283, 1-22 (1972)

Almeida, G.P., Durao, D.F.G., Heitor, M.V.: Wake flows behind two-dimensional model hills. Exp. Therm. Fluid Sci. 7, 87-101 (1993). doi:10.1016/0894-1777(93)90083-U

Aminzadeh, M., Or, D.: Temperature dynamics during nonisothermal evaporation from drying porous surfaces. Water Resour. Res. 49 (2013). doi:10.1002/2013WR014384

Bange, G.G.J.: On the quantitative explanation of stomatal transpiration. Acta Bot. Neerl. 2(3), 255-296 (1953)

Baskaran, V., Smits, A.J., Joubert, P.N.: A turbulent flow over a curved hill Part 1. Growth on an internal boundary layer. J. Fluid Mech. 182, 47-83 (1987). doi:10.1017/S0022112087002246

Bradshaw, P.: Effects of streamline curvature on turbulent flow. Agardograph. AGARDograph 169, 1-131 (1973)

Breugem, W.P., Boersma, B.J., Uittenbogaard, R.E.: The influence of wall permeability on turbulent channel flow. J. Fluid Mech. 562, 35-72 (2006). doi:10.1017/S0022112006000887

Bowers, S.A., Hanks, R.J.: Reflection of radiant energy from soils. Soil Sci. 100(2), 130-138 (1965). doi:10. 1097/00010694-196508000-00009

Bristow, K.L., Campbell, G.S., Papendick, R.I., Elliott, L.F.: Simulation of heat and moisture transfer through a surface residue-soil system. Agric. For. Meteorol. 36, 193-214 (1986). doi:10.1016/ 0168-1923(86)90035-3

Brutsaert, W.: A theory for local evaporation (or heat transfer) from rough and smooth surfaces at ground level. Water Resour. Res. 11(4), 543-550 (1975). doi:10.1016/0009-2509(73)85083-3

Buckles, J., Hanratty, T.J., Adrian, R.J.: Turbulent flow over large-amplitude wavy surfaces. J. Fluid Mech. 140, 27-44 (1984). doi:10.1017/S0022112084000495

Cherukat, P., Na, Y., Hanratty, T.J., McLaughlin, J.B.: Direct numerical simulation of a fully developed turbulent flow over a wavy wall. Theor. Comput. Fluid Dyn. 11, 109-134 (1998). doi:10.1007/s001620050083

Cierniewski, J., Karnieli, A., Kazmierowski, C., Krolewicz, S., Piekarczyk, J., Lewinska, K., Goldberg, A., Wesolowski, R., Orzechowski, M.: Effects of soil surface irregularities on the diurnal variation of soil broadband blue-sky albedo. IEEE J. Sel. Top. Appl. Earth Obs. Remote Sens. (2014). doi:10.1109/ JSTARS.2014.2330691

Cooke, J.R.: Some theoretical considerations in stomatal diffusion: a field theory approach. Acta Biotheor. 17, 95-124 (1967). doi:10.1007/BF01625092

Danckwerts, P.V.: Significance of liquid-film coefficients in gas absorption. J. Ind. Eng. Chem. 43, 1460-1467 (1951). doi:10.1021/ie50498a055

Finnigan, J.J.: Air flow over complex terrain. In: Steffen, W.L., Denmead, O.T. (eds.) Flow and Transport in the Natural Environment: Advances and Applications, pp. 183-229. Springer, Heidelberg (1988)

Gaikovich, K.P.: Study of atmospheric-turbulence effects on the formation of a thermal film in the near-surface water layer and the dynamics of air-water heat exchange using measurements of thermal radio emission. Radiophys. Quantum Electron. 43(6), 469-477 (2000). doi:10.1007/BF02677174 
Gill, K.S., Jalota, S.K., Prihar, S.S., Chaudhary, T.N.: Water conservation by soil mulch in relation to soil type, time of tillage, tilth and evaporativity. J. Ind. Soc. Soil Sci. 25, 360-366 (1977)

Guzha, A.C.: Effects of tillage on soil microrelief, surface depression storage and soil water storage. Soil Tillage Res. 76, 105-114 (2004). doi:10.1016/j.still.2003.09.002

Haghighi, E., Shahraeeni, E., Lehmann, P., Or, D.: Evaporation rates across a convective air boundary layer are dominated by diffusion. Water Resour. Res. 49, 1602-1610 (2013). doi:10.1002/wrcr.20166

Haghighi, E., Or, D.: Evaporation from porous surfaces into turbulent airflows: coupling eddy characteristics with pore scale vapor diffusion. Water Resour. Res. 49, 8432-8442 (2013). doi:10.1002/2012WR013324

Haghighi, E., Or, D.: Thermal signatures of turbulent airflows interacting with evaporating thin porous surfaces. Int. J. Heat Mass Transf. 87, 429-446 (2015). doi:10.1016/j.ijheatmasstransfer.2015.04.026

Haghighi, E., Or, D.: Linking evaporative fluxes from bare soil across surface viscous sublayer with the Monin-Obukhov atmospheric flux-profile estimates. J. Hydrol. 525, 684-693 (2015). doi:10.1016/j. jhydrol.2015.04.019

Harriott, P.: A Random eddy modification of the penetration theory. Chem. Eng. Sci. 17, 149-154 (1962). doi:10.1016/0009-2509(62)80026-8

Hartmann, D.L.: Global Physical Climatology. Academic Press, San Diego (1994)

Higbie, R.: The rate of absorption of a pure gas into a still liquid during short periods of exposure. Trans. AIChE 31, 365-388 (1935)

Holmes, J.W., Greacen, E.L., Gurr, G.C.: The evaporation of water from bare soils with different tilths. In: Transactions on 7th international congress of soil science, vol. 1, pp. 188-194. Madison, WI, International Society of Soil Science, Wageningen, The Netherlands (1960)

Jalota, S.K., Prihar, S.S.: Bare-soil evaporation in relation to tillage. In: Stewart, B.A. (ed.) Advances in Soil Science, vol. 12, pp. 187-216. Springer, New York (1990)

Kalma, J.D., McVicar, T.R., McCabe, M.F.: Estimating land surface evaporation: a review of methods using remotely sensed surface temperature data. Surv. Geophys. 29, 421-469 (2008). doi:10.1007/ s10712-008-9037-z

Kimball, B.A., Lemon, E.R.: Air turbulence effects upon soil gas exchange. Soil Sci. Soc. Am. J. 35, 16-21 (1971). doi:10.2136/sssaj1971.03615995003500010013x

Kruse, N., Kuhn, S., von Rohr, P.R.: Wavy wall effects on turbulence production and large-scale modes. J. Turbul. 7, 1-24 (2006). doi:10.1080/14685240600602911

Lehmann, P., Assouline, S., Or, D.: Characteristic lengths affecting evaporative drying of porous media. Phys. Rev. E 77(5), 056309 (2008). doi:10.1103/PhysRevE.77.056309

Lehrsch, G.A., Whisler, F.D., Römkens, M.J.M.: Soil surface roughness as influenced by selected soil physical properties. Soil Tillage Res. 10, 197-212 (1987). doi:10.1016/0167-1987(87)90028-6

Leij, F.J., Alves, W.J., van Genuchten, M.T., Williams, J.R.: The UNSODA unsaturated soil hydraulic database. In: van Genuchten, M.T., Leij, F.J., Wu, L. (eds. ) Proceedings of international workshop characterization and measurement of the hydraulic properties of unsaturated porous media, pp. 1269-1281, UC Riverside (1999)

Linden, D.R.: Predicting tillage effects on evaporation. In: Unger, P.W., Van Doren D.M. (eds.) Predicting Tillage Effects on Soil Physical Properties and Processes, vol. 44, American Society of Agronomy, Soil Science Society of America, ASA Special Publication, Madison, WI (1982)

Maßß, C., Schumann, U.: Direct numerical simulation of separated turbulent flow over a wavy boundary. In: Hirschel, E.H. (ed.) Flow Simulation with High Performance Computers, pp. 227-241. Vieweg, Braunschweig (1996)

Massman, W.J., Sommerfeld, R.A., Mosier, A.R., Zeller, K.F., Hehn, T.J., Rochelle, S.G.: A model investigation of turbulence-driven pressure-pumping effects on the rate of diffusion of $\mathrm{CO}_{2}, \mathrm{~N}_{2} \mathrm{O}$, and $\mathrm{CH}_{4}$ through layered snowpacks. J. Geophys. Res. 102(D15), 18851-18863 (1997). doi:10.1029/97JD00844

Matthias, A.D., Fimbres, A., Sano, E.E., Post, D.F., Accioly, L., Batchily, A.K., Ferreira, L.G.: Surface roughness effects on soil albedo. Soil Sci. Soc. Am. J. 64, 1035-1041 (2000). doi:10.2136/sssaj2000.6431035x

McInnes, K.J., Heilman, J.L., Savage, M.J.: Aerodynamic conductances along a bare ridge-furrow tilled soil surface. Agric. For. Meteorol. 68, 119-131 (1994). doi:10.1016/0168-1923(94)90031-0

Meek, R.L., Baer, A.D.: The periodic viscous sublayer in turbulent flow. AIChE J. 16(5), 841-848 (1970). doi:10.1002/aic.690160525

Meek, R.L., Baer, A.D.: Turbulent heat transfer and the periodic viscous sublayer. Int. J. Heat Mass Transf. 16(7), 1385-1396 (1973). doi:10.1016/0017-9310(73)90146-4

Mira, M., Valor, E., Boluda, R., Caselles, V., Coll, C.: Influence of soil water content on the thermal infrared emissivity of bare soils: implication for land surface temperature determination. J. Geophys. Res. 112, F04003 (2007). doi:10.1029/2007JF000749

Mirzaei, M., Davidson, L., Sohankar, A., Innings, F.: The effect of corrugation on heat transfer and pressure drop in channel flow with different Prandtl numbers. Int. J. Heat Mass Transf. 66, 164-176 (2013) 
Mualem, Y.: A new model for predicting the hydraulic conductivity of unsaturated porous media. Water Resour. Res. 12(3), 513-522 (1976). doi:10.1029/WR012i003p00513

Mwendera, E.J., Feyen, J.: Tillage and evaporativity effects on the drying characteristics of a silty loam: evaporation prediction models. Soil Tillage Res. 41, 127-140 (1997). doi:10.1016/S0167-1987(96)01078-1

Oke, T.R.: Boundary Layer Climates. Methuen, London (1978)

Penman, H.L.: Natural evaporation from open water, bare soil and grass. Proc. R. Soc. A. 193, 120-145 (1948). doi:10.1098/rspa.1948.0037

Perry, A.E., Schofield, W.H., Joubert, P.N.: Rough wall turbulent boundary layers. J. Fluid Mech. 37, 383-413 (1969)

Popovich, A.T., Hummel, R.L.: Experimental study of the viscous sublayer in turbulent pipe flow. AIChE J. 13(5), 854-860 (1967). doi:10.1002/aic.690130509

Potter, K.N., Horton, R., Cruse, R.M.: Soil surface roughness effects on radiation reflectance and soil heat flux. Soil Sci. Soc. Am. J. 51, 855-860 (1987). doi:10.2136/sssaj1987.03615995005100040003x

Prat, M.: Recent advances in pore-scale models for drying of porous media. Chem. Eng. J. 86, 153-164 (2002). doi:10.1016/S1385-8947(01)00283-2

Qiu, G., Yano, T., Momii, K.: An improved methodology to measure evaporation from bare soil based on comparison of surface temperature with a dry soil. J. Hydrol. 210, 93-105 (1998). doi:10.1016/ S0022-1694(98)00174-7

Qiu, G.Y., Zhao, M.: Remotely monitoring evaporation rate and soil water status using thermal imaging and "three-temperatures model (3T model)" under field-scale conditions. J. Environ. Monit. 12, 716-723 (2010). doi:10.1039/b919887c

Raupach, M.R., Wenig, W.S., Carruthers, D.J., Hunt, J.C.R.: Temperature and humidity fields and fluxes over low hills. Q. J. R. Meteorol. Soc. 118, 191-225 (1992). doi:10.1002/qj.49711850403

Raupach, M.R., Finnigan, J.J.: The influence of topography on meteorological variables and surfaceatmosphere interactions. J. Hydrol. 190, 182-213 (1997). doi:10.1016/S0022-1694(96)03127-7

Raupach, M.R.: Drag and drag partition on rough surfaces. Bound. Lay. Meteorol. 60, 375-395 (1992). doi:10. 1007/BF00155203

Reul, N., Branger, H., Giovanangeli, J.P.: Air flow structures over short-gravity breaking water waves. Bound. Lay. Meteorol. 126, 477-505 (2008). doi:10.1007/s10546-007-9240-3

Seo, Y.G., Lee, W.K.: Single-eddy model for random surface renewal. Chem. Eng. Sci. 43(6), 1395-1402 (1988). doi:10.1016/0009-2509(88)85112-1

Schlünder, E.U.: On the mechanism of the constant drying rate period and its relevance to diffusion controlled catalytic gas phase reactions. Chem. Eng. Sci. 43(10), 2685-2688 (1988). doi:10.1016/ 0009-2509(88)80012-5

Schultz, M.P., Flack, K.A.: Turbulent boundary layers on a systematically varied rough wall. Phys. Fluids 21, 015104 (2009). doi:10.1063/1.3059630

Schwartz, R.C., Baumhardt, R.L., Evett, S.R.: Tillage effects on soil water redistribution and bare soil evaporation throughout a season. Soil Tillage Res. 110, 221-229 (2010). doi:10.1016/j.still.2010.07.015

Shahraeeni, E., Or, D.: Thermo-evaporative fluxes from heterogeneous porous surfaces resolved by infrared thermography. Water Resour. Res. 46(9), W09511 (2010). doi:10.1029/2009WR008455

Shahraeeni, E., Lehmann, P., Or, D.: Coupling of evaporative fluxes from drying porous surfaces with air boundary layer: characteristics of evaporation from discrete pores. Water Resour. Res. 48, W09525 (2012). doi:10.1029/2012WR011857

Shokri, N., Lehmann, P., Vontobel, P., Or, D.: Drying front and water content dynamics during evaporation from sand delineated by neutron radiography. Water Resour. Res. 44, W06418 (2008). doi:10.1029/ 2007WR006385

Shokri, N., Lehmann, P., Or, D.: Liquid phase continuity and solute concentration dynamics during evaporation from porous media-pore scale processes near vaporization surface. Phys. Rev. E. 81, 046308 (2010). doi:10.1103/PhysRevE.81.046308

Simpson, R.L.: Turbulent boundary-layer separation. Ann. Rev. Fluid Mech. 21, 205-234 (1989)

Taylor, P.A., Gent, P.R.: A model of atmospheric boundary layer flow above an isolated two-dimensional hill: an example of flow over gentle topography. Bound. Lay. Meteorol. I, 349-362 (1974). doi:10.1007/ BF00240837

Tuoc, T.K., Keey, R.B.: A modified penetration theory and its relation to boundary layer transport. Trans. IChemE 70(A), 596-603 (1992)

Unger, P.W., Cassel, D.K.: Tillage implement disturbance effects on soil properties related to soil and water conservation: a literature review. Soil Tillage Res. 19,363-382 (1991). doi:10.1016/0167-1987(91)90113-C

van Brakel, J.: Mass transfer in convective drying. In: Mujumdar, A.S. (ed.) Advances in Drying, vol. 1, pp. 217-267. Hemisphere, New York (1980) 
van Genuchten, MTh: A closed-form equation for predicting the hydraulic conductivity of unsaturated soils. Soil Sci. Soc. Am. J. 44(5), 892-898 (1980). doi:10.2136/sssaj1980.03615995004400050002x

Wagner, C., Kenjeres, S., von Rohr, P.R.: Dynamic large eddy simulations of momentum and wall heat transfer in forced convection over wavy surfaces. J. Turbul. 12, N7 (2011). doi:10.1080/14685248.2010.547496

Wieringa, J.: Representative roughness parameters for homogeneous terrain. Bound. Lay. Meteorol. 63, 323363 (1993). doi:10.1007/BF00705357

Willis, W.O., Bond, J.J.: Soil water evaporation: reduction by simulated tillage. Soil Sci. Soc. Am. Proc. 35, 526-528 (1971). doi:10.2136/sssaj1971.03615995003500040016x

Yang, B.P.S., Blackwell, Nicholson, D.F.: A numerical model of heat and water movement in furrow-sown water repellent sandy soils. Water Resour. Res. 32(10), 3051-3061 (1996). doi:10.1029/96WR02103

Yiotis, A.G., Stubos, A.K., Boudouvis, A.G., Yortsos, Y.C.: A 2-D pore-network model of the drying of single-component liquids in porous media. Adv. Water Resour. 24, 439-460 (2001). doi:10.1016/ S0309-1708(00)00066-X

Zilker, D.P., Hanratty, T.J.: Influence of the amplitude of a solid wavy wall on a turbulent flow. Part 1. Nonseparated flows. J. Fluid Mech. 82, 29-51 (1977). doi:10.1017/S0022112077000524

Zilker, D.P., Hanratty, T.J.: Influence of the amplitude of a solid wavy wall on a turbulent flow. Part 2. Separated flows. J. Fluid Mech. 90, 257-271 (1979). doi:10.1017/S0022112079002196 